\title{
Article \\ Effect of Na- and Organo-Modified Montmorillonite/Essential Oil Nanohybrids on the Kinetics of the In Situ Radical Polymerization of Styrene
}

\author{
Ioannis S. Tsagkalias ${ }^{1}$, Alexandra Loukidi ${ }^{1}$, Stella Chatzimichailidou ${ }^{1}$, Constantinos E. Salmas ${ }^{2} \mathbb{D}$, \\ Aris E. Giannakas ${ }^{3}$ (D) and Dimitris S. Achilias ${ }^{1, *(D)}$ \\ 1 Department of Chemistry, Aristotle University of Thessaloniki, 54124 Thessaloniki, Greece; \\ itsagka108@gmail.com (I.S.T.); loukidialexia@gmail.com (A.L.); stedimcha@chem.auth.gr (S.C.) \\ 2 Department of Material Science \& Engineering, University of Ioannina, 45110 Ioannina, Greece; \\ ksalmas@uoi.gr \\ 3 Department of Food Science and Technology, University of Patras, 30100 Agrinio, Greece; \\ agiannakas@upatras.gr \\ * Correspondence: axilias@chem.auth.gr; Tel.: +30-231-099-7822
}

\section{check for} updates

Citation: Tsagkalias, I.S.; Loukidi, A.; Chatzimichailidou, S.; Salmas, C.E.;

Giannakas, A.E.; Achilias, D.S. Effect of Na- and Organo-Modified

Montmorillonite/Essential Oil

Nanohybrids on the Kinetics of the In Situ Radical Polymerization of Styrene. Nanomaterials 2021, 11, 474. https://doi.org/10.3390/nano11020474

Academic Editor: Ana

María Díez-Pascual

Received: 14 January 2021

Accepted: 9 February 2021

Published: 13 February 2021

Publisher's Note: MDPI stays neutral with regard to jurisdictional claims in published maps and institutional affiliations.

Copyright: (c) 2021 by the authors. Licensee MDPI, Basel, Switzerland. This article is an open access article distributed under the terms and conditions of the Creative Commons Attribution (CC BY) license (https:/ / creativecommons.org/licenses/by/ $4.0 /)$.

\begin{abstract}
The great concern about the use of hazardous additives in food packaging materials has shown the way to new bio-based materials, such as nanoclays incorporating bioactive essential oils (EO). One of the still unresolved issues is the proper incorporation of these materials into a polymeric matrix. The in situ polymerization seems to be a promising technique, not requiring high temperatures or toxic solvents. Therefore, in this study, the bulk radical polymerization of styrene was investigated in the presence of sodium montmorillonite (NaMMT) and organo-modified montmorillonite (orgMMT) including thyme (TO), oregano (OO), and basil (BO) essential oil. It was found that the hydroxyl groups present in the main ingredients of $\mathrm{TO}$ and $\mathrm{OO}$ may participate in side retardation reactions leading to lower polymerization rates (measured gravimetrically by the variation of monomer conversion with time) accompanied by higher polymer average molecular weight (measured via GPC). The use of BO did not seem to affect significantly the polymerization kinetics and polymer MWD. These results were verified from independent experiments using model compounds, thymol, carvacrol and estragol instead of the clays. Partially intercalated structures were revealed from XRD scans. The glass transition temperature (from DSC) and the thermal stability (from TGA) of the nanocomposites formed were slightly increased from 95 to $98^{\circ} \mathrm{C}$ and from 435 to $445^{\circ} \mathrm{C}$, respectively. Finally, better dispersion was observed when orgMMT was added instead of NaMMT.
\end{abstract}

Keywords: polymerization kinetics; polystyrene; Na-montmorillonite; organo-modified montmorillonite; thyme oil; oregano oil; basil oil

\section{Introduction}

In recent years, the great concern about the use of hazardous and/or toxic additives in food packaging materials has led the scientific community to search for new bio-based compounds to be used in active plastic packaging. Among natural antioxidants, essential oils are the most widely used materials in the food packaging industry [1]. To this direction, hybrids of montmorillonite (MMT) with essential oils (EO) have been prepared recently in order to be used in active packaging because of their controllable and long-life antioxidant activity [2-9].

Essential oils are volatile, natural liquids with oily texture that can be extracted from several plants $[10,11]$. Due to the aroma character of EOs, they have been widely used in cosmetic industry [10]. In addition, the large bioactivity of EOs has being confirmed by several studies and includes antibacterial, anti-inflammatory, antifungal, antimutagenic, antineoplasmatic and antioxidant activities, along with other miscellaneous activities [12]. 
Oregano (Origanum vulgare L.) [13], thyme (Thymus vulgaris L.) and basil (Ocimum basilicum) are aromatic plants with a wide distribution throughout the Mediterranean area and especially Greece [14]. The oregano essential oils comprise more than 20 ingredients, most of which are phenolic antioxidants [15] having antimicrobial [16] properties. The primarily components of oregano essential oil are carvacrol and thymol ranging to over $80 \mathrm{wt} \%$, while less abundant compounds include p-cymene, $\gamma$-terpinene, caryophyllene, spathulenol, germacrene-D, $\beta$-fenchyl alcohol and $\delta$-terpineol [17]. Thyme oil, the essential oil of common thyme, containing mainly the phenols thymol and carvacrol [18], while in small quantities p-cymene, myrcene, borneol, and linalool [19]. Most of them show antioxidant and antimicrobial properties against a broad spectrum of gram-negative or gram-positive bacteria. Similarly, basil essential oil consists of more than 30 compounds with the main constituent being estragole $[20,21]$. Basil EO has been proved to exhibit antimicrobial effect against different bacteria [22] and against different fungi [23].

In order to incorporate additives, such as antioxidants, in a polymer matrix usually the melt mixing technique in screw extruders is used in industry. However, use of volatile materials, for example essential oils, in such processes is restricted due to their possible rapid loss via evaporation [24-26]. A controlled release of EO into the polymers would be required to overcome this rapid decline of activity. Therefore, it was anticipated that the required controlled release and protection against polymer processing conditions could be provided when the EOs are adsorbed onto an inorganic porous material $[7,27]$. Nanomontmorillonite (MMT) has been proposed as an ideal adsorbent and nano-carrier of EOs due to its high cation exchange capacity, high surface area and ability to swell [28-30]. Accordingly, several essential oils, including those from oregano (OO), thyme (TO) and basil (BO) were encapsulated in sodium montmorillonite (NaMMT) and commercially available organo-modified montmorillonite (orgMMT). The prepared NaMMTEO and orgMMTEO nanohybrids exhibited controllable and sustained antioxidant activity. Furthermore, they were melt-blended with low-density polyethylene (LDPE) to form packaging films with potential antioxidant properties. Indeed, these films retained up to $50-70 \%$ of their antioxidant activity after six months of incubation [8].

Synthesis of polymer-based nano-composites has been the subject of many investigations recently and various techniques have been developed [31-34]. Three of them are the most studied, namely, melt blending, solution mixing and in-situ polymerization. Melt-blending is the most industrially used technique since it does not require any additional equipment and can be integrated in any plastics producing factory. However, temperatures above the melting point of the polymer are needed, while a homogeneous distribution of nanometer-scale particles in highly viscous polymer melts is difficultly achieved and particle aggregation cannot be avoided. The second technique is rather simple and extensively used (mainly in laboratory experiments) though usually large amounts of potentially toxic solvents are needed. In the in situ polymerization, a good dispersion of the usually-modified layered silicate in the liquid monomer is initially achieved, resulting in homogeneous dispersion of the nano-additive in the polymer matrix. This makes it an attractive alternative route not requiring high temperatures to melt the polymer. The monomer migrates into the layered silicate galleries and polymerization often occurs between the intercalated sheets. When both intra- and extra-gallery polymerization takes place, the clay layers are delaminated and exfoliated nanocomposites can be formed. The in situ polymerization in the presence of several nano-additives was the subject of extensive experimental work by our group [35-39]. The main concern with this technique has to do with the fact that some specific functional groups present on the nanofiller surface could react with the radicals generated during polymerization. In fact, it has been found that primary initiator radicals may react with hydroxyl groups present on the surface of graphene oxide resulting in lower polymerization rates $[39,40]$. In addition, the presence of layered silica inside the reacting mixture may affect diffusion-controlled phenomena taking place during the reaction [35]. 
Polystyrene (PS) is a high transparent, hard, brittle and low strength polymer, used for the manufacturing of disposable containers in food packaging, where it comes in two forms, rigid and foam. Molded polystyrene used to produce the rigid form find applications as protective packaging in such products as clear food containers for dairy products, salad bars, etc., plates, bowls, disposable beverage cups and their lids, egg cartons, food trays, straws, etc. Because, of its low gas barrier, PS can be used when a breathable film is required. Expanded polystyrene in foam form (usually known by its trade name styrofoam ${ }^{\mathrm{TM}}$ ) is used for take-out foods, plates, insulated beverage cups and bowls, hinged containers ("clamshells") and cafeteria trays. Foods packaged in PS include yogurt, ice cream, coffee, fruit juices, and meat and fresh products. It can be recognized it by its recycling code of 6 .

In order to examine if the in situ polymerization could be used as an effective technique to prepare nanocomposite materials based on sodium montmorillonite NaMMTEO or organo-modified montmorillonite (orgMMTEO) nanohybrids the bulk radical polymerization kinetics of polystyrene was investigated here. Thus, NaMMTEO and orgMMTEO nanostructures with medium (60 wt \%), and high (80 wt \%) EO nominal content were used as additives to styrene polymerized at a specific temperature using benzoyl peroxide as initiator. Polymerization kinetics was investigated gravimetrically by recording the variation of monomer conversion with time. The PS/NaMMTEO and PS/orgMMTEO nanohybrids were characterized using a variety of experimental techniques including, $\mathrm{X}$-ray diffraction (XRD), FTIR spectroscopy, gel permeation chromatography (GPC), differential scanning calorimetry (DSC) and thermogravimetric analysis (TGA). In this way it was challenging to check how surface functional groups of the EOs could affect the kinetics ant the properties of the prepared polymer nanocomposites. Furthermore, in order to discriminate between the effect of the MMT itself or the characteristic compounds of the essential oils on the reaction kinetics and polymer properties, additional experiments carried out using styrene and model thymol, carvacrol and estragol this time. It should be emphasized here that, according to our knowledge, this is the first study on the polymerization kinetics of styrene in the presence of nano-montmorillonite including essential oils of thyme, oregano and basil.

\section{Materials and Methods}

\subsection{Materials}

The monomer used, i.e., styrene (S) with a purity $\geq 99 \%$ was purchased from Merck Schuchardt, Darmstadt, germany (Index-No: 601-026-00-0) and the hydroquinone inhibitor was removed by passing it, at least twice, through disposable inhibitor-remover packed columns, supplied from Aldrich, Darmstadt, Germany. The free radical initiator, benzoyl peroxide (BPO) with a purity $>97 \%$ (CAS: 94-36-0) was provided by Alfa Aesar, Kandel, Germany and purified by fractional recrystallization twice from methanol (from Riedel-de Haen, Munich, Germany). Dichloromethane and methanol used in the dissolution and re-precipitation of the polymer were purchased from Alfa Aesar, Kandel, Germany.

Origanum (OO), thyme (TO) and basil (BO) essential oils were purchased from Esperis spa., Greece according to safety data sheets, the \% mass composition of oregano oil was $60-70 \%$ carvacrol, 10-12.5\% thymol, 10-12.5\% paracymene, 5-7\% alpha-pinene, 5-7\% 1-Isopropyl-4-methyl-1,4-cyclohexadiene p-Mentha-1,4-diene and 1-3\% terpinen-4olo, beta-myrcene and (R)-p-mentha-1,8-diene. Thyme oil consisted of 50-60\% thymol, 15-20\% para-cymene, 10-12.5\% 1-Isopropyl-4-methyl-1,4-cyclohexadiene p-Mentha-1,4diene, 3-5\% carvacrol and 1-3\% linalool, beta caryophyllene, beta-myrcene, (R)-p-mentha1,8-diene, alpha-pinene, borneol and terpinen-4-olo. Basil oil consisted of 70-80\% estragol, 7.5-10\% linalool, 1-3\% eukalyptol, $0.5-1.0 \%$ eugenol and $0.5-1.0 \%$ D-limonene. In addition, model compounds thymol (Sigma-Aldrich, Darmstadt, Germany, purity >99\%), Carvacrol (Sigma-Aldrich, Darmstadt, Germany, purity >99\%) and estragol (Siga-Aldrih, Darmstadt, Germany, purity $>97 \%$ ) were used. The chemical structure of the main components of the three EO used, i.e., thymol, carvacrol and estragol appear in Scheme 1. 
<smiles>C=CCc1ccc(OC)cc1</smiles>

Scheme 1. Chemical structure of thymol, carvacrol and estragol.

Two types of clay were used: (i) sodium exchanged montmorillonite (NaMMT) with code name Nanomer ${ }^{\circledR}$ PGV with mass density $2.6 \mathrm{~g} / \mathrm{cm}^{3}$ and CEC value $145 \mathrm{meq} / 100 \mathrm{~g}$ produced by Nanocor Inc. 2870 Forbs Avenue Hoffman Estates, IL, USA and supplied by Sigma-Aldrich, Darmstadt, Germany. The chemical composition of NaMMT was $62.9 \%$ $\mathrm{SiO}_{2}, 19.6 \% \mathrm{Al}_{2} \mathrm{O}_{3}, 3.35 \% \mathrm{Fe}_{2} \mathrm{O}_{3}, 3.05 \% \mathrm{MgO}, 1.68 \% \mathrm{CaO}, 1.53 \% \mathrm{Na}_{2} \mathrm{O}$. (ii) organo-modified montmorillonite (orgMMT) NANOMER ${ }^{\circledR}$-I.44P produced by Nanocor Inc. 2870 Forbs Avenue Hoffman Estates, IL USA and supplied by Sigma-Aldrich, Darmstadt, Germany. NANOMER ${ }^{\circledR}$-I.44P is an -onium ion modified clay containing $\sim 40 \mathrm{wt} \%$ dimethyl dialkyl (C14-18) ammonium organic modifier.

All other chemicals used were of analytical grade and were used as received without further purification.

\subsection{Preparation of NaMMT/EO and orgMMT/EO Hybrids}

Loading of EO into NaMMT and orgMMT was carried out via an adsorption/evaporat ion procedure without the addition of organic solvents [7]. Before the adsorption/evaporat ion procedure, NaMMT and orgMMT were dried for $24 \mathrm{~h}$ in $120^{\circ} \mathrm{C}$, and then $5 \mathrm{~g}$ of each clay was spread in an aluminum beaker. In the middle of the aluminum beaker a smaller quartz beaker was placed and was filled with appropriate quantity of each EO. The amount of EO used was 3.0, or $4.0 \mathrm{~g}$ to achieve final nominal composition of $\mathrm{EO}$ to clays 60 and $80 \mathrm{wt} \%$ respectively. Then, the aluminum beaker was sealed and put in an oven at $120^{\circ} \mathrm{C}$ for $24 \mathrm{~h}$. Under these conditions the most volatile EO components were evaporated and adsorbed into NaMMT and orgMMT (nonvolatile fraction was $\sim 30-60 \%$ ). When the evaporation-adsorption procedure ended (after $24 \mathrm{~h}$ ) the obtained NaMMT/EO and OrgMMT/EO clay hybrids were labeled and put in sealed closed glass beakers for further characterization.

\subsection{Preparation of the Initial Monomer/MMT Mixtures}

The monomer (S) with the sodium MMT or the organomodified MMT, were positioned to ultrasonication (in Transsonic $460 \mathrm{H}$ ultrasonic bath from Elma) for one hour, so that to have a satisfactory colloidal dispersion of the clay to the solution. In the final suspension, the initiator, BPO $0.03 \mathrm{M}$ was added and the mixture degassed by passing nitrogen and immediately used.

\subsection{Synthesis of PS/MMTEO Nanocomposites by the In-Situ Bulk Radical Polymerization Technique}

For the preparation of the nanocomposite materials both sodium (NaMMT) and organomodified montmorillonite (orgMMT) were used at a percentage $3.0 \mathrm{wt} \%$ relative to monomer. The amount of montmorillonite added was kept in a relatively low percentage, since according to literature nano-MMT can significantly improve the properties of a nanocomposite material even at very low loadings [40]. Three essential oils were loaded to MMT, from thyme, oregano and basil at two nominal composition of EO to clay 60 and $80 \mathrm{wt} \%$ respectively. Code names and the details of the chemical conditions that were used for the preparation of all NaMt/EO and OrgMt/EO clay hybrids were included in Table 1. All clays, before polymerization were placed in an oven for $1 \mathrm{~h}$ at $80^{\circ} \mathrm{C}$ for the removal 
of water possibly adsorbed in their surface. Afterwards, they were stored in desiccators until use.

Table 1. Designation and amounts (wt \%) of oregano oil, thyme oil, basil oil and sodium montmorillonite (NaMMT) or organo-modified montmorillonite (orgMMT) used for the preparation of all NaMMTEO hybrids and orgMMTEO hybrids.

\begin{tabular}{ccccc}
\hline Sample & NaMMT/orgMMT (\% & & Nominal Composition of EO to Clays (\%) \\
\cline { 3 - 5 } & Relative to Monomer) & Basil & Thyme & Oregano \\
\hline PS & - & - & - & - \\
PS/orgMMT & 3 & - & - & - \\
PS/orgMMTBO60 & 3 & 60 & 60 & - \\
PS/orgMMTTO60 & 3 & - & - & - \\
PS/orgMMTOO60 & 3 & - & - & - \\
PS/orgMMTBO80 & 3 & 80 & 80 & - \\
PS/orgMMTTO80 & 3 & - & - & - \\
PS/orgMMTOO80 & 3 & - & - & - \\
PS/NaMMT & 3 & - & 60 & - \\
PS/NaMMTBO60 & 3 & 60 & - & - \\
PS/NaMMTTO60 & 3 & - & - & - \\
PS/NaMMTOO60 & 3 & - & 80 & - \\
PS/NaMMTBO80 & 3 & 80 & - & \\
PS/NaMMTTO80 & 3 & - & & \\
PS/NaMMTOO80 & 3 & - & & - \\
\hline
\end{tabular}

In order to study the reaction kinetics, the in situ, bulk, free radical polymerization technique was employed. Polymerization was carried out in small test-tubes by heating the initial monomer-clay-initiator mixture at $80{ }^{\circ} \mathrm{C}$ for a suitable time. Polymerization temperature was kept constant in all experiments. According to this technique, $1 \mathrm{~mL}$ of the pre-weighed mixture of monomer with the initiator and each amount of clay were placed into a series of 10 small test-tubes. After degassing with nitrogen, they were sealed and placed into a pre-heated bath at the desired polymerization temperature. Each test-tube was removed from the bath at the pre-specified time intervals and was immediately frozen, after the addition of a few drops of hydroquinone, in order to stop the reaction. The product was isolated after dissolution in $\mathrm{CH}_{2} \mathrm{Cl}_{2}$ and re-precipitation in $\mathrm{MeOH}$. Subsequently, all isolated materials were dried to constant weight in a vacuum oven at room temperature. All final samples were weighed and the degree of conversion was estimated gravimetrically. Duplicate experiments were run in order to check the reproducibility of the results.

Neat polymer (PS) was also synthesized under the same experimental conditions and used as reference material.

\subsection{Synthesis of Composites Based on PS with Model Thymol, Carvacrol and Estragol}

In order to check the effect of the main constituents of the essential oils, i.e., thymol, carvacrol and estragol alone on the polymerization kinetics of styrene, additional experiments were carried out using exactly the same experimental conditions (i.e., temperature, initiator, polymerization technique, etc.). Instead of the clay nanohybrids, different amounts of the three compounds were used each time. The amount of thymol, carvacrol and estragol added were $0.1,0.5$ and $1.0 \mathrm{wt} \%$ based on the monomer styrene. Relatively low percentages were used in order to be in the same order of magnitude with previous experiments. The materials produced were given the code names PS/Thym0.1, PS/Thym0.5, PS/Thym1.0, PS/Carv0.1, PS/Carv0.5, PS/Carv1.0, PS/Estr0.1, PS/Estr0.5 and PS/ESTR1.0 depending on the compound added and its percentage.

\subsection{Measurements}

X-ray diffraction. X-ray diffraction (XRD) was used to characterize the crystalline structure of MMT and the prepared PS/MMTEO materials. The instrument used was a Rigaku 
Miniflex II, (Chalgrove, Oxford, UK) equipped with CuKa generator $(\lambda=0.1540 \mathrm{~nm})$. The XRD patterns were recorded at the range $2 \theta=2-30^{\circ}$ with scan speed of $2^{\circ} \mathrm{min}^{-1}$.

Fourier-transform infra-red (FTIR) spectroscopy. The chemical structure of neat PS and its nanocomposites with the clay and the clay/essential oil hybrid materials was confirmed by recording their IR spectra. The instrument used was the Spectrum 1 spectrophotometer (Perkin Elmer, Waltham, MA, USA) with an attenuated total reflectance (ATR) device. Spectra were recorded over the range from 4000 to $650 \mathrm{~cm}^{-1}$ at a resolution of $2 \mathrm{~cm}^{-1}$ and 32 scans were averaged to reduce noise. The instrument's software was used to identify the peaks.

Gel permeation chromatography (GPC). GPC was used to determine the molecular weight distribution (MWD) and the average molecular weights of neat PS and all the nanocomposites of PS with NaMMTEO and orgMMTEO. The instrument used was the PL-GPC 50 Plus from Polymer Laboratories (Church Stretton, UK). It includes an isocratic pump, three PLgel $5 \mu$ MIXED-C columns together with a guard pre-column in series and a differential refractive index detector. The elution solvent was tetrahydrofuran (THF) at a constant flow rate of $1 \mathrm{~mL} \mathrm{~min}^{-1}$. All samples were dissolved in this solvent at a constant concentration of $1 \mathrm{mg} \mathrm{mL}^{-1}$. After filtration, $200 \mu \mathrm{L}$ of each sample was injected into the chromatograph. The column oven was kept at a constant temperature of $30{ }^{\circ} \mathrm{C}$. Standard polystyrene samples were used for the calibration of GPC (obtained from Polymer Laboratories).

Thermogravimetric analysis (TGA). The thermal stability of the samples was measured by recording the mass loss with increasing temperature via thermogravimetric analysis. The instrument used was Pyris 1 TGA (from Perkin-Elmer, Waltham, MA, USA). Samples of about 8-10 mg were used and they were heated from ambient temperature to $600{ }^{\circ} \mathrm{C}$ at a heating rate of $20^{\circ} \mathrm{C} \mathrm{min}^{-1}$ under nitrogen flow.

Differential scanning calorimetry (DSC). DSC was used to estimate the glass transition temperature of each material prepared. The instrument used was the DSC-Diamond (from Perkin-Elmer, Waltham, MA, USA). Approximately 5-6 mg of each sample were weighed, put into the standard Perkin-Elmer sample pan, sealed and placed into the appropriate position of the instrument. Subsequently, a cycle heating-cooling-re-heating was used. The temperature program used included: heating from ambient temperature to $180{ }^{\circ} \mathrm{C}$ at a rate of $10^{\circ} \mathrm{C} \mathrm{min}^{-1}$ to ensure complete polymerization of the residual monomer, cooling from 180 to $30^{\circ} \mathrm{C}$ at the same rate and heating again from 30 to $130{ }^{\circ} \mathrm{C}$ at a rate of $20^{\circ} \mathrm{C} \mathrm{min}-1$. The glass transition temperature was measured from the second heating, using the half $\mathrm{Cp}$ interpolation method.

\section{Results}

\subsection{Characterization of the PS/MMTEO Nanocomposites}

Polymer-clay nanocomposites can be classified as immiscible (tactoids), intercalated, partially exfoliated, or exfoliated, depending on the clay content, the chemical nature of the organic modifier, and the synthetic method [35]. In order to identify possible exfoliation or intercalation of the clays due to the presence of the essential oils, XRD measurements were carried for neat PS, the orgMMT and the nanocomposites of PS/orgMMT, PS/orgMMTEO, $\mathrm{PS} / \mathrm{NaMMT}$ and PS/NaMMTEO. XRD patterns were recorded in the angle range of $2 \theta$ from $2^{\circ}$ to $30^{\circ}$ and indicative spectra are shown in Figure 1. The amorphous structure of polystyrene was identified by the presence of a very broad peak at $19.5^{\circ}$. When orgMMT or NaMMT with the EOs was incorporated into the polymer matrix, similar spectra were recorded for all nanocomposites in the range from $5^{\circ}$ to $30^{\circ}$, meaning that all materials produced still present an amorphous structure. 


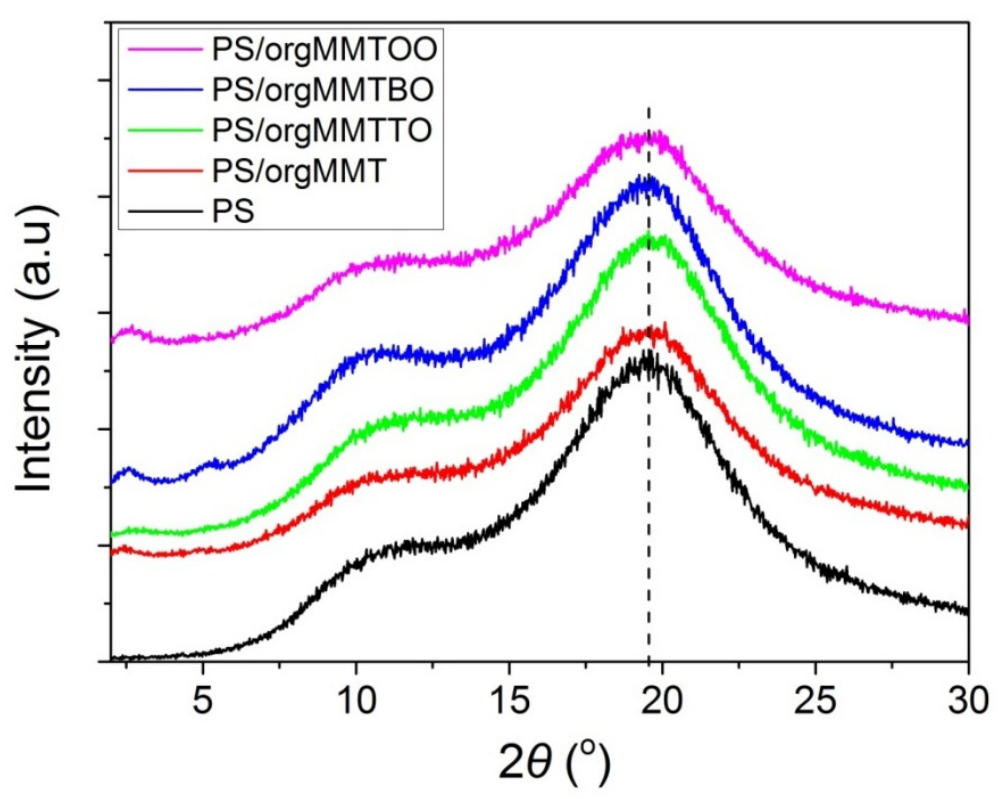

Figure 1. X-ray diffraction patterns of neat polystyrene (PS) and its nanocomposites with $3 \%$ orgMMT, orgMMTBO, orgMMTTO and orgMMTOO over the full range of $2 \theta$ from 2 to $30^{\circ}$.

Furthermore, we focused on small angles to investigate the morphology of the clay in the nanocomposite. The results are illustrated in Figure 2a,b. The orgMMT shows a sharp peak at $3.5^{\circ}$ (Figure 2a) corresponding to d-spacing of $2.52 \mathrm{~nm}$. The value measured in our previous publication was $2.8 \mathrm{~nm}$ [7]. Furthermore, the 001 reflections (Figure 2a) of all PS/orgMMTEO nanocomposites showed a rather small peak near $2.6^{\circ}$ (ranging from $2.6^{\circ}$ to $2.64^{\circ}$ ) and the calculated $\mathrm{d}_{001}$-spacing value using Bragg's law was $3.4 \mathrm{~nm}$ (ranging from 3.34 to $3.4 \mathrm{~nm}$ ). Therefore, an increase of the basal spacing in orgMMT was observed due to the insertion of the EO and further polymerization. This is an indication that intercalated structures were obtained when initially the EOs were inserted between the clay layers and furthermore due to polymerization from the insertion of macromolecular chains. An increase of d-spacing from 2.8 to $3.6 \mathrm{~nm}$ was observed in neat organomodified clay when the hybrid materials with the specific essential oils were produced [7]. Similar spectra were recorded for all EOs. Additionally, when organomodified clay was added to PMMA during in situ polymerization an increase of $\mathrm{d}_{001}$-spacing from 2.9 to $3.5 \mathrm{~nm}$ was measured [35]. Therefore, the values measured here are similar to those previously reported for similar systems and it is suggested that the nanocomposites can be considered as partially intercalated. For the PS/NaMMT material small peaks appeared at $2.5^{\circ}$ and $4.6^{\circ}$, whereas for all the PS/NaMMTEO based nanocomposites no clear peaks were observed (Figure $2 b$ ) meaning that a rather exfoliated structure was obtained.

Furthermore, in order to characterize the materials formed and confirm various functional groups, the FTIR spectra of all nanocomposites were measured and results compared to pristine PS. Indicative curves appear in Figure 3. For pristine PS (Figure 3a) the characteristic peaks observed at 3082,3060 and $3026 \mathrm{~cm}^{-1}$ are assigned as aromatic stretching vibrations, $v(\mathrm{C}-\mathrm{H})_{\mathrm{ar}}$. The characteristic absorption bands at 2924 and $2850 \mathrm{~cm}^{-1}$ are assigned to aliphatic $\mathrm{C}-\mathrm{H}$ stretching vibrations, $v(\mathrm{C}-\mathrm{H})$. The other peaks at 1493 and $1452 \mathrm{~cm}^{-1}$ to $\mathrm{C}=\mathrm{C}$ stretching vibrations, $v(\mathrm{C}-\mathrm{C})$. Mono substituted benzene are obtained at $\delta(\mathrm{C}-\mathrm{H})_{\mathrm{ar}} 756 \mathrm{~cm}^{-1}$ and $\gamma_{\text {ring }} 698 \mathrm{~cm}^{-1}$. All these values are in accordance to corresponding literature data $[41,42]$. 


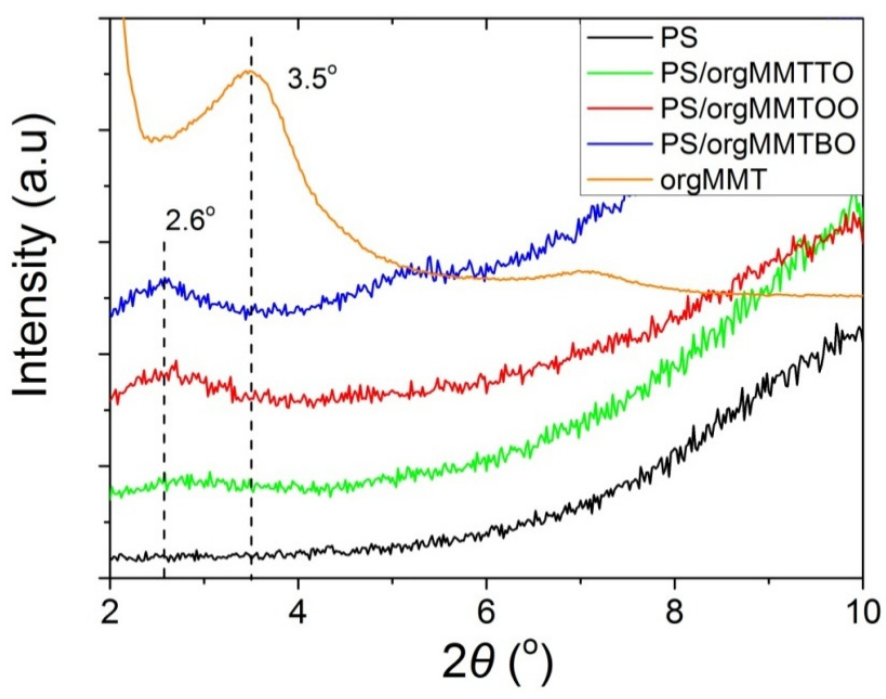

(a)

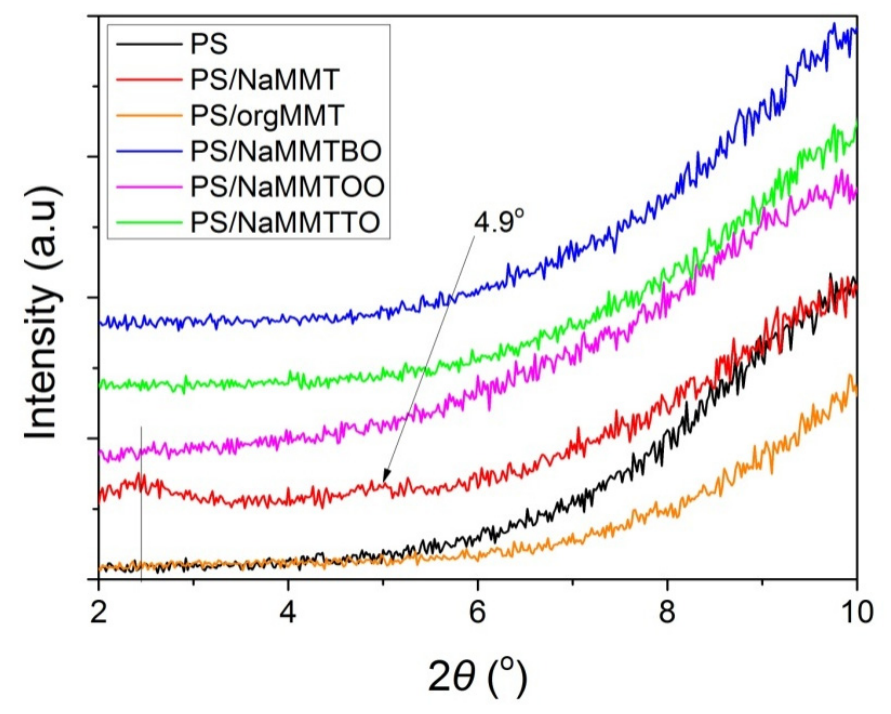

(b)

Figure 2. XRD patterns of organomodified MMT (orgMMT), neat PS and PS with $3 \%$ orgMMTEO nanocomposites (a) and of PS with NaMMTEO nanocomposites (b) focusing on the $2 \theta$ range from $2^{\circ}$ to $10^{\circ}$.
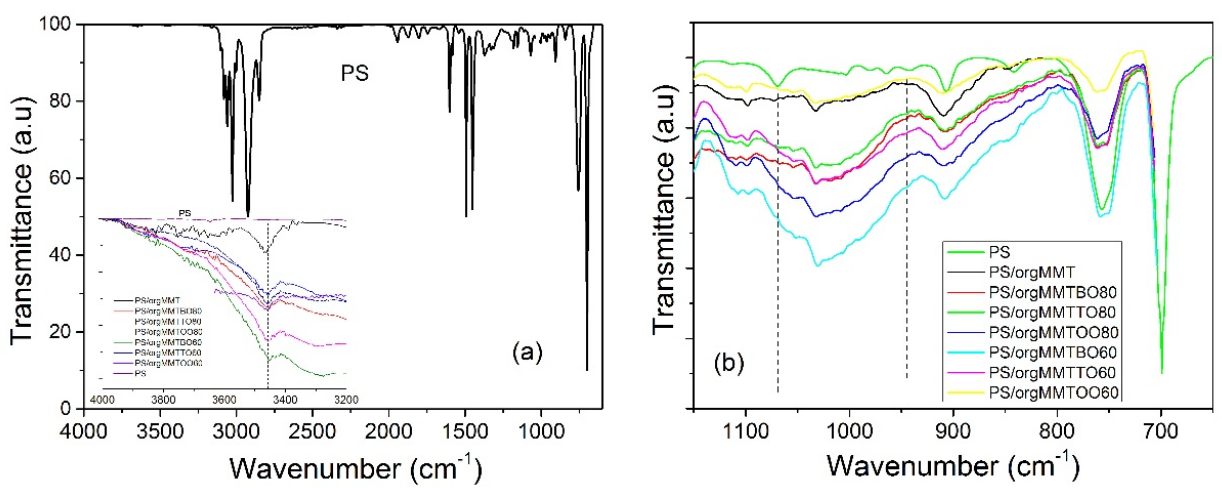

Figure 3. FTIR spectra of neat PS (a) and PS/orgMMTEO nanocomposites in the wavenumber range $4000-3200 \mathrm{~cm}^{-1}$ (a) and $1150-650 \mathrm{~cm}^{-1}$ (b). 
In the embedded figure in Figure 3a a broad peak at wavenumber $3457 \mathrm{~cm}^{-1}$ appears in all nanocomposites, not present in neat $\mathrm{PS}$, which is designated as the $\mathrm{O}-\mathrm{H}$ stretching modes of interlayer $\mathrm{H}_{2} \mathrm{O}$ molecules. Compared to pristine PS the nanocomposites show a new broad band ranging from 1069 to $944 \mathrm{~cm}^{-1}$ indicating Si-O stretching (Figure 3b). It should be pointed here that peaks were very weak due to the low amount of the clay inside the polymer matrix $(3 \%)$. From these indicative peaks, the presence of organoclay in the PS polymer is confirmed.

\subsection{Polymerization Kinetics}

Polymerization kinetics was followed by recording the variation of monomer conversion with time. In order to investigate the effect of the clays with the essential oils on the polymerization of styrene, a brief review of the reaction mechanism and kinetics is presented next.

As it is well-known, polymerization of styrene follows the typical radical polymerization mechanism including the following elementary reactions:

Initiation (thermal decomposition of the initiator, I, to form two benzoyloxy primary radicals, $\left.R^{*}\right)$<smiles>[R]C(=O)c1ccc(Cc2ccc(C(=O)OOC(=O)c3ccccc3)cc2)cc1</smiles>

Further, the benzoyloxy radicals react with the double bond of a monomer molecule to initiate polymerization:<smiles>O=C(OCCc1ccccc1)c1ccc(C(=C[PH2+])c2ccccc2)cc1</smiles>

Propagation (radicals react with monomer molecules to form long radical chains):

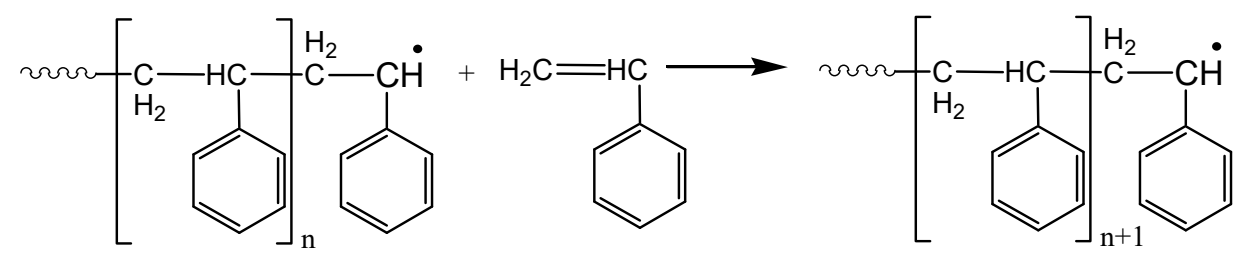

Termination (two macroradicals react to form a dead polymer molecule)

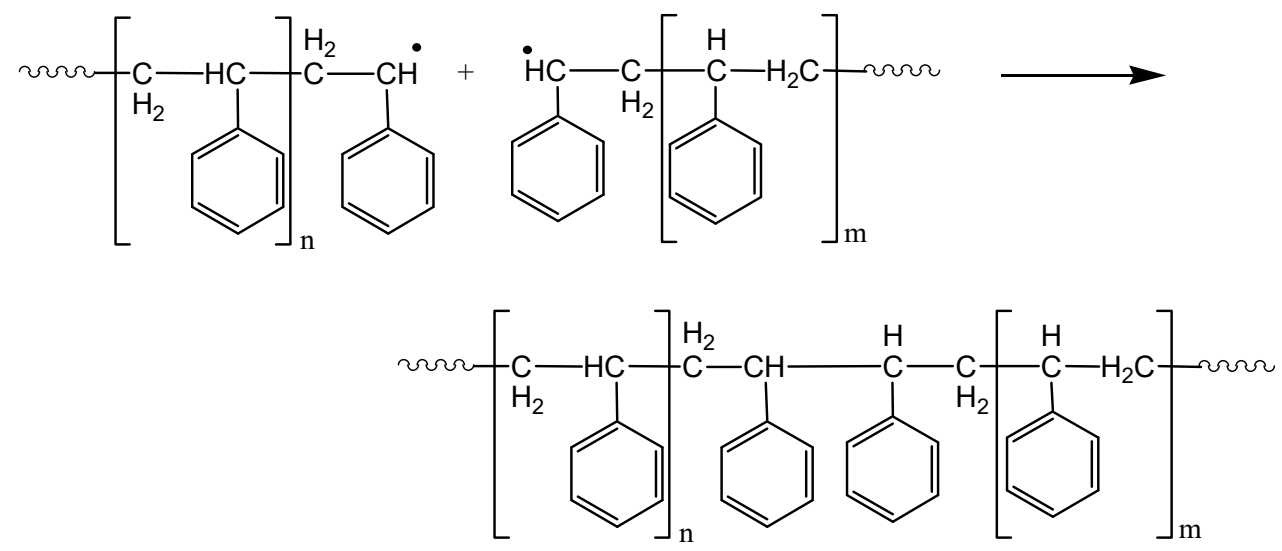


It should be noted that termination may take place by combination (as it is shown in the reaction above) or by disproportionation with transfer of a $\beta$-Hydrogen and formation of a terminal double bond. However, in polystyrene, termination by combination is the dominant mechanism of termination. Furthermore, chain transfer to monomer reactions may take place, though they are not so important during polymerization of styrene.

Based on the above reaction mechanism, the polymerization rate, denoted by the variation of monomer conversion, $X$ with time, $t$ can be expressed by the following equation, [43].

$$
\frac{d X}{d t}=\left(k_{p}+k_{t r M}\right)\left(\frac{f k_{d}[I]}{k_{t}}\right)^{1 / 2}(1-X)
$$

where $k_{d}, k_{p}, k_{t r M}$ and $k_{t}$ denote the kinetic rate coefficients of the initiator decomposition, propagation, chain transfer to monomer and termination reactions, $f$ is the initiator's efficiency. Note that in Equation (1) for simplicity reasons the steady-state approximation for the initiator primary radicals and the total radical population has been applied, which have been proven to hold at low monomer conversions. The initiator concentration, [I], varies with time according to:

$$
\frac{d[I]}{d t}=-k_{d}[I] \Rightarrow[I]=[I]_{0} \exp \left(-k_{d} t\right)
$$

In order to integrate Equation (1) and provide an expression for the variation of monomer conversion with time, all kinetic rate coefficients and $f$ are assumed independent of conversion. This is correct at low monomer conversions, where diffusion-controlled phenomena do not affect the polymerization kinetics. Then, by replacing Equations (2) to (1) and integrating, one gets:

$$
X=1-\exp \left[2 k_{e f f}\left(1-e^{-k_{d} t / 2}\right)\right]
$$

with

$$
k_{e f f}=\left(k_{p}+k_{t r M}\right)\left(\frac{f[I]_{0}}{k_{d} k_{t}}\right)^{1 / 2}
$$

The kinetic rate constants for the polymerization of styrene can be evaluated from the following Arrhenius expressions, denoting variation only with the reaction temperature, $\mathrm{T}: k_{p}=4.27 \times 10^{7} \exp (-32,500 / \mathrm{RT}) \mathrm{L} / \mathrm{mol} / \mathrm{s}, k_{t}=1.255 \times 10^{6} \exp (-846 / \mathrm{T}) \mathrm{L} / \mathrm{mol} / \mathrm{s}$, $k_{d}=5 \times 10^{16} \exp (-143,000 / \mathrm{RT}) \mathrm{s}^{-1}, k_{t r M}=5 \times 10^{-5} k_{p}$ and $f=1$ [44]. All experiments in this study were performed at $80{ }^{\circ} \mathrm{C}$. At this temperature, the values of the above kinetic rate constants, are: $k_{p}=664.5 \mathrm{~L} / \mathrm{mol} / \mathrm{s}, k_{t}=1.14 \times 10^{8} \mathrm{~L} / \mathrm{mol} / \mathrm{s}, k_{d}=3.5 \times 10^{-5} \mathrm{~s}^{-1}$, $k_{t r M}=0.033 \mathrm{~L} / \mathrm{mol} / \mathrm{s}$ and $\mathrm{f}=1$. Then, the variation of monomer conversion with time can be theoretically estimated from Equation (3) setting the initial initiator concentration as $[I]_{0}=0.03 \mathrm{~mol} / \mathrm{L}$.It should be pointed here that Equation (3) is valid only at low monomer conversions where diffusion-controlled phenomena do not affect the chemical reactions.

The experimental data showing the effect of adding sodium or organomodified clay on the PS polymerization kinetics are illustrated in Figure 4. Results of the theoretical model, according to Equation (3), are also included in this figure as a continuous line. It is obvious that the theoretical model simulates very well the experimental data of neat polystyrene at low monomer conversions. This is also verification that the experimental measurements are accurate. Therefore, it seems that typical radical polymerization kinetics is followed for this monomer until almost $40 \%$ conversion. Afterwards, an increase in the conversion values and as a result of the reaction rate is observed. This is ascribed to the well-studied auto-acceleration phenomenon or gel-effect. Accordingly, when a significant amount of macromolecular chains are produced, chain entanglements hinder the movement of macroradicals to find one another and terminate. Therefore, radical bimolecular termination is reduced due to the presence of the polymer chains, resulting in a local increase of their concentration. Hence, according to equation (1), the polymerization 
rate is enhanced resulting in higher conversion vales at the same reaction time. At very high conversions, beyond $90 \%$, even the movement of the small monomer molecules or the initiator primary radicals is hindered. This results in reduced propagation of monomers or reduced initiator efficiency leading to a polymerization rate tending to zero before the full consumption of the monomer. This phenomenon is more pronounced when the polymerization temperature $\left(80{ }^{\circ} \mathrm{C}\right.$ in this investigation) is below the glass transition temperature of the polymer (near $95^{\circ} \mathrm{C}$ for PS) and is reported as glass-effect. Thus final monomer conversions are always less than 100\% [44].

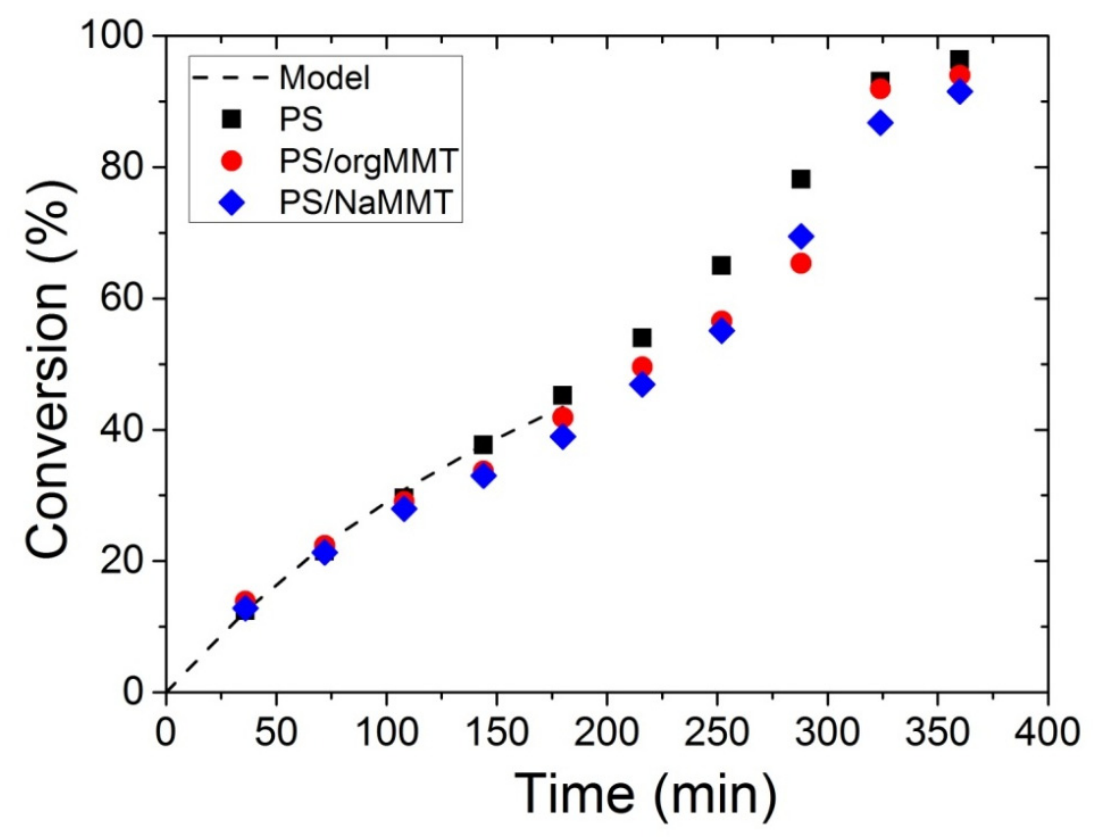

Figure 4. Variation of conversion with time of neat PS and PS/NaMMT or PS/orgMMT at $80{ }^{\circ} \mathrm{C}$ with initiator BPO at $0.03 \mathrm{M}$ showing the effect of the nanoclays on the bulk polymerization kinetics of PS. The straight line represents result of the theoretical kinetic model.

From Figure 4 it is clear that addition of the neat nanoclay results in a slight reduction of the polymerization rate compared to neat PS. This has been also observed in literature and is attributed to the fact that nano-clay may act as a radical scavenger resulting in slightly reduced radical concentrations and as a result to slightly lower conversion values [44,45].

The effect of adding the nano-clays with the EOs on the polymerization kinetics of PS appears in Figure 5. Generally, visually it was observed that, the nano-additives based on the organomodified MMT presented a good dispersion of the nanoclays into the polymer matrix and a homogeneous suspension was obtained. In contrast, when using the sodium MMT the dispersion was not so good even after intense stirring. The variation of conversion with time was not affected much when the basil EO was used. However, a significant reduction in polymerization rate was obvious when using the oregano or thyme oil and the reduction followed the amount of the essential oil present in the clay. From the chemical composition of the three EOs used, it seems that the presence of phenols, such as thymol or carvacrol in large amounts in thyme oil and oregano oil seems to be the main reason for the reduction of the polymerization rate when using $\mathrm{TO}$ or $\mathrm{OO}$. In contrast the main component of BO, i.e., estragol does not contain hydroxyl groups. Specifically, the presence of hydroxyl groups in these substances seems to result in side reactions with the radicals. It is known that, phenols may play a role as inhibitors in radical polymerization reactions. However, the question here is whether phenolic hydroxyls present in thymol or carvacrol react with the macro-radicals or with the primary radicals formed from the decomposition of the initiator. Moreover, do they react as chain transfer agents, inhibitors, or retarders? When a compound acts as a chain transfer agent in a radical polymerization 
mechanism, then it reduces the average molecular weight of the polymer but it does not affect polymerization rate since the small radicals produced can find a monomer molecule with equal reactivity as the initiator primary radicals. This is not the case here since polymerization rate was reduced. Hence the concept of chain transfer reaction is abandoned. Inhibitors are compounds that completely stop the polymerization by reacting with the radicals formed and not permitting them to find monomer molecules and start polymerization. This again was not the case here since an induction time was not observed. Then, it seems that thymol and carvacrol present in the essential oils TO and OO play the role of reaction retarder, meaning that they reduce the polymerization rate by reacting with radicals and the new radicals formed can propagate polymerization but in a lower rate.

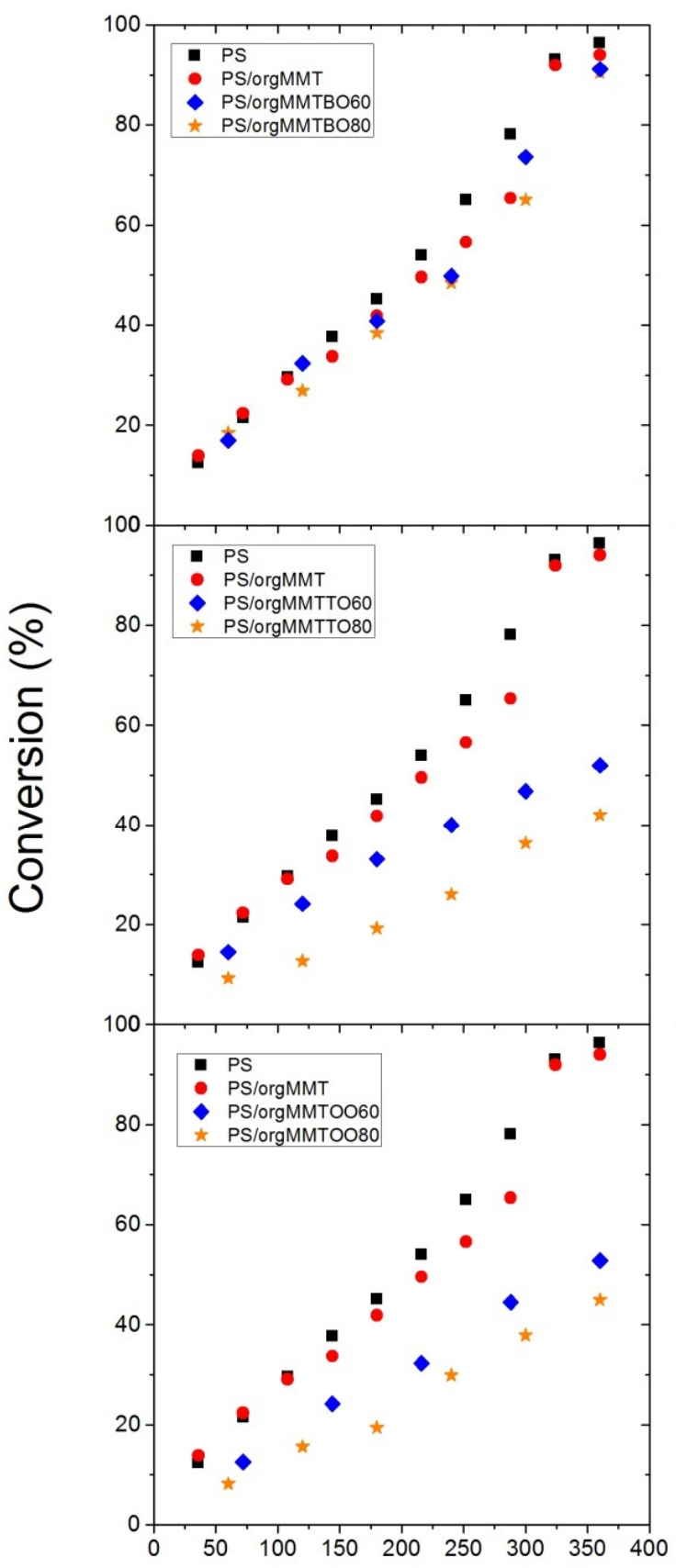

Polymerization time (min)

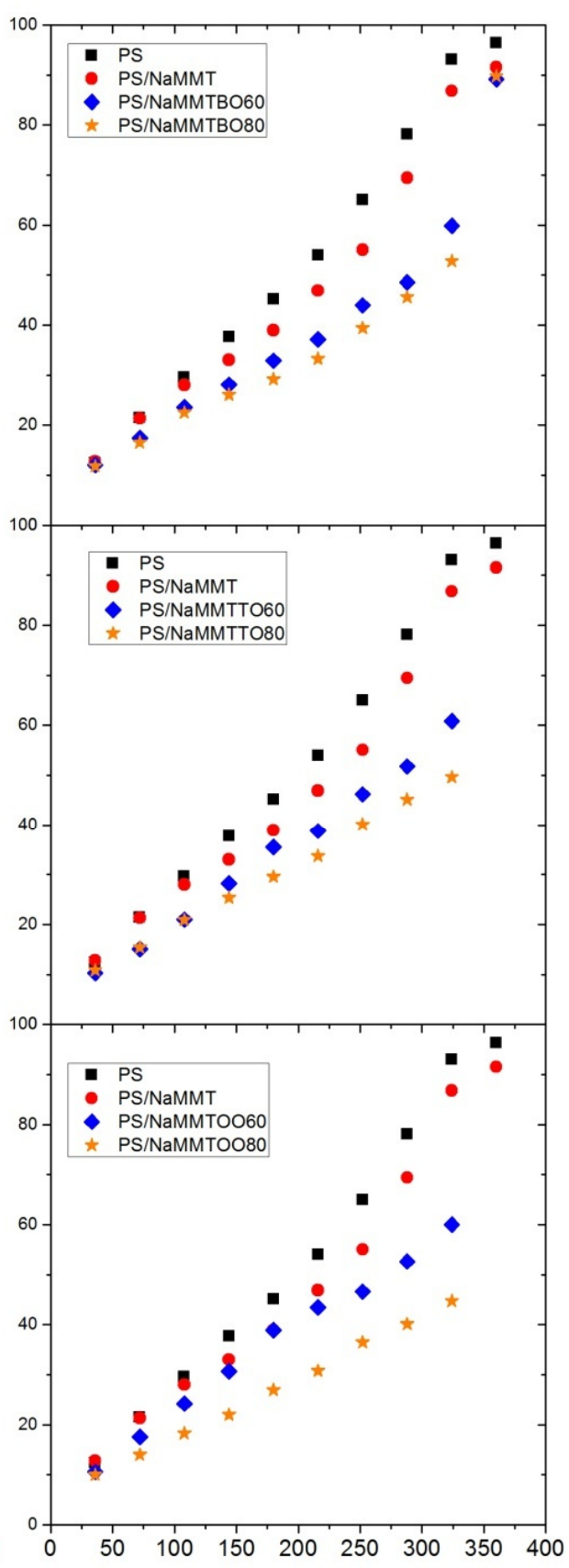

Polymerization time (min)

Figure 5. Variation of monomer conversion with time during polymerization of styrene at $80{ }^{\circ} \mathrm{C}$ with $0.03 \mathrm{~mol} / \mathrm{L}$ initial BPO concentration. The left column presents results when the orgMMT with the essential oils was added, whereas the right column when the NaMMT with the EOs was added. 
In order to identify if the macro-radicals or the primary radicals are those that mainly react with the hydroxyl groups in retardation reactions, we performed additional measurements of the average molecular weight of the polymer formed. Accordingly, if macroradicals take part in such reactions then they will eventually stop increasing in length through propagation resulting in polymer with lower average molecular weight. If primary initiator radicals take part in retardation reactions with the hydroxyl groups then it is the initiator efficiency that will be reduced since not all radicals produced from the decomposition of the initiator will eventually react with monomer molecules to form long chains. To clear the picture the theoretical equation providing the number average molecular weight of a polymer was considered. This can be estimated from the number average degree of polymerization, which, in the case of termination by combination, is the double of the average kinetic chain length, $v$ :

$$
\frac{1}{v}=\frac{k_{t}\left[P^{\bullet}\right]}{k_{p}[M]}+\frac{k_{t r M}[M]}{k_{p}[M]}=\frac{\left(f k_{d}[I] k_{t}\right)^{1 / 2}}{k_{p}[M]}+C_{M}
$$

It should be noted here that Equation (5) provides the instantaneous average kinetic chain length which is correct at low conversion where diffusion-controlled phenomena are not present. According to Equation (5), if the initiator efficiency, $f$, is decreased then the kinetic chain length, $v$ and as a result the polymer number average molecular weight will be in increased. The physical picture behind this is that, if the number of primary initiator radicals is reduced and since they potentially can react with the same number of monomer molecules it will eventually result to a lower number of macro-radicals though with a higher chain length.

The molecular weight distribution (MWD) and the average molecular weights of neat PS and all nano-hybrids were measured with GPC and results are presented in Figure 6 and Table 2. The number average molecular weight, Mn, of neat PS was measured at 37,120 and increased to 44,680 when orgMMT was added. This is a clear indication that orgMMT acts as a radical scavenger, in accordance with previous findings for the in situ MMA homopolymerization in the presence of organomodified montmorillonite $[35,36]$. Moreover, the addition of the clays with basil essential oil, orgMMTBO60 or orgMMTBO80 resulted in slightly higher values of the number average molecular weight. However, this increase was much pronounced when the essential oils of oregano or thyme were used. Actually, $\mathrm{M}_{\mathrm{N}}$ increased from 44,680 to 52,200 and 61,380 when orgMMTTO60 and orgMMTTO80 were used and to 56,870 and 73,860 when orgMMTOO60 and orgMMTOO80 were used. This can be clearly seen in Figure 6, where a shift of the distribution to higher values is clear. In contrast, the MWD for PS/orgMMTBO was almost the same with that of PS/orgMMT. This is a clear indication that the presence of the hydroxyl groups in carvacrol and thymol which are placed in the galleries of the MMT can be more easily accessed by the small primary initiator radicals resulting in decreased initiator efficiency and thus to polymers with fewer macomolecular chains having higher molecular weight. A schematic representation of the phenomenon appears in Scheme 2.

Using chemical reactions the above observations can be explained as follows: The phenoxy radicals formed from the reaction of an initiator primary radicals, $R^{*}$ with the hydroxyl groups of thymol or carvacrol present in TO or OO may further react either with another primary initiator radical or with a macro-radical to form inactive species (Scheme 3). The presence of more hydroxyl groups results in lower initiator efficiency, $f$ and as a result to higher average molecular weight of the polymer. This mechanism explains the lower polymerization rate together with the higher average molecular weight measured in the orgMMTOO and orgMMTTO samples. 

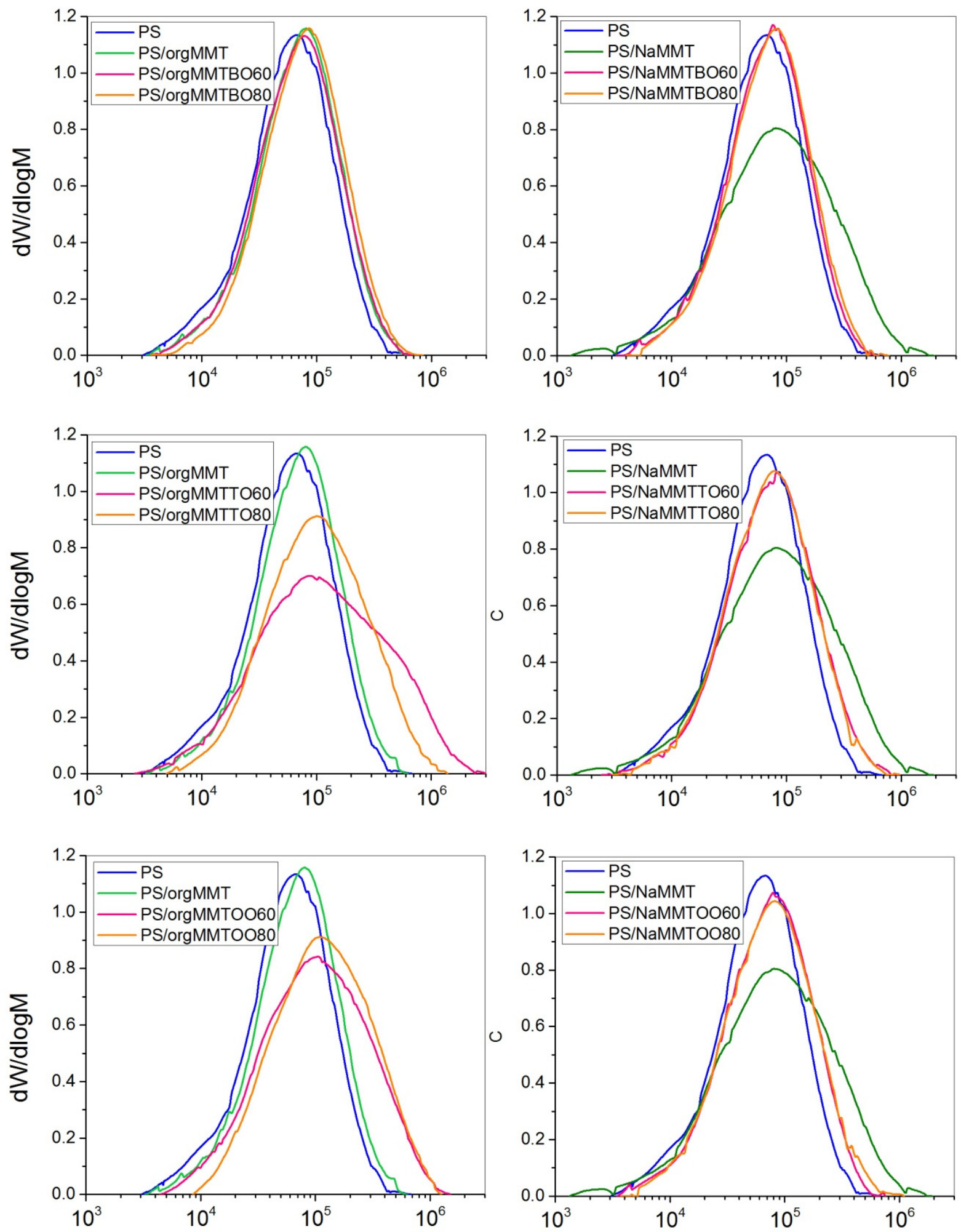

\section{Molecular Weight}

Figure 6. Molecular weight distribution of neat PS and its nanocomposites with either orgMMTBO, orgMMTTO, orgMMTOO (left column), or NaMMTBO, NaMMTOO and NaMMTTO (right column). 
Table 2. Number- and weight-average molecular weights $\left(\bar{M}_{n}, \bar{M}_{w}\right)$, as well as polydispersity of the MWD (PD) together with the glass transition temperature $\left(\mathrm{T}_{\mathrm{g}}\right)$ of neat PS and its nanocomposites with the sodium or organo-modified montmorillonite (MMT) with or without the essential oils.

\begin{tabular}{ccccc}
\hline Sample & $-\boldsymbol{M}_{\boldsymbol{n}}$ & - & PD & $\mathbf{T}_{\mathbf{g}}\left({ }^{\circ} \mathbf{C}\right)$ \\
\hline PS & 37,120 & 77,590 & 2.09 & 94.5 \\
PS/orgMMT & 44,680 & 90,300 & 2.02 & 97.2 \\
PS/orgMMTBO60 & 45,310 & 90,460 & 2.00 & 97.6 \\
PS/orgMMTTO60 & 52,200 & 222,610 & 4.26 & 98.0 \\
PS/orgMMTOO60 & 56,870 & 159,830 & 2.81 & 97.2 \\
PS/orgMMTBO80 & 50,010 & 100,520 & 2.01 & 99.7 \\
PS/orgMMTTO80 & 61,380 & 152,420 & 2.48 & 99.8 \\
PS/orgMMTOO80 & 73,860 & 173,160 & 2.34 & 98.5 \\
PS/NaMMT & 38,610 & 140,120 & 3.63 & 96.0 \\
PS/NaMMTBO60 & 44,070 & 86,450 & 1.96 & 97.1 \\
PS/NaMMTTO60 & 45,750 & 100,440 & 2.20 & 96.8 \\
PS/NaMMTOO60 & 44,960 & 96,390 & 2.14 & 99.3 \\
PS/NaMMTBO80 & 47,510 & 91,830 & 1.93 & 98.9 \\
PS/NaMMTTO80 & 45,900 & 97,260 & 2.12 & 98.2 \\
PS/NaMMTOO80 & 47,810 & 102,900 & 2.15 & \\
\hline
\end{tabular}
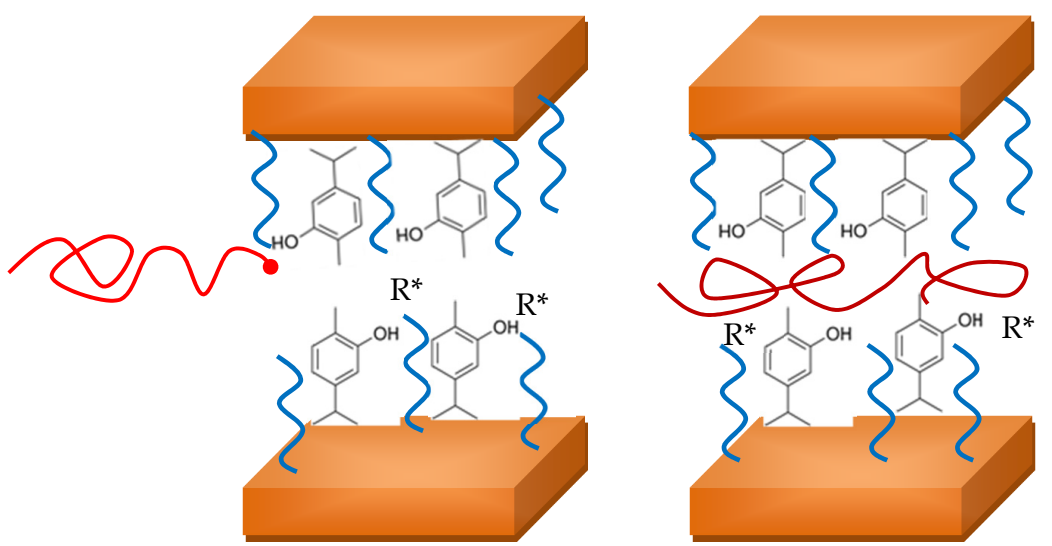

Scheme 2. Possible chemical reactions of the primary initiator radicals, $R^{*}$ or the macro-radicals with the hydroxyl groups of compounds in the essential oils inside the clay galleries of the organo-modified montmorillonite.

Finally, from Figure 6 and Table 2 it is seen that using the NaMMT with the essential oils only a slight increase in the polymer average molecular weight was observed. The MWD is slightly shifted to higher values. This is because in this case mainly macro-radicals react with the hydroxyl groups and not primary radicals thus the initiator efficiency is not reduced significantly.

Furthermore, in order to check if the compounds of the essential oils or the clay are responsible for the specific effect on polymerization kinetics of styrene additional experiments carried out using model thymol, carvacrol and estragol at several relative to styrene percentages. Results on the variation of conversion with time appear in Figure 7 . It is clear the effect of estragol on the variation of conversion with time is negligible. However, the effect of either carvacrol or thymol is very important. Specifically polymerization rate is significantly reduced and this phenomenon is more intense when the amount of the compound is increased. Therefore, these results verify the hypothesis shown in Scheme 3 that primary initiator radicals and to a lesser extend macroradicals react with the hydroxyl groups of these compounds resulting in lower radical concentration and hence lower polymerization rate. In a final attempt to reinforce these results in Figure $7 \mathrm{~d}$ the conversion vs. time profiles obtained from the orgMMTEO with the higher amount of the EO are compared to those obtained when using $1.0 \%$ of each model compound. It is very 
interesting that similar results were obtained in each essential oil with the corresponding model compound. Finally, the average molecular weight of the polymer formed was measured with GPC and results are illustrated in Table 3. It is seen that in accordance with previous findings the effect of adding estragol was negligible. However, adding either thymol or carvacrol results in an increase in the average molecular weight of the polymer formed. Meaning again that, the initiator primary radicals react with the phenol hydroxyl groups resulting in lower initiator efficiency and hence lower macromolecular chains having higher degree of polymerization. The polydispersity of the MWD was not changed significantly.

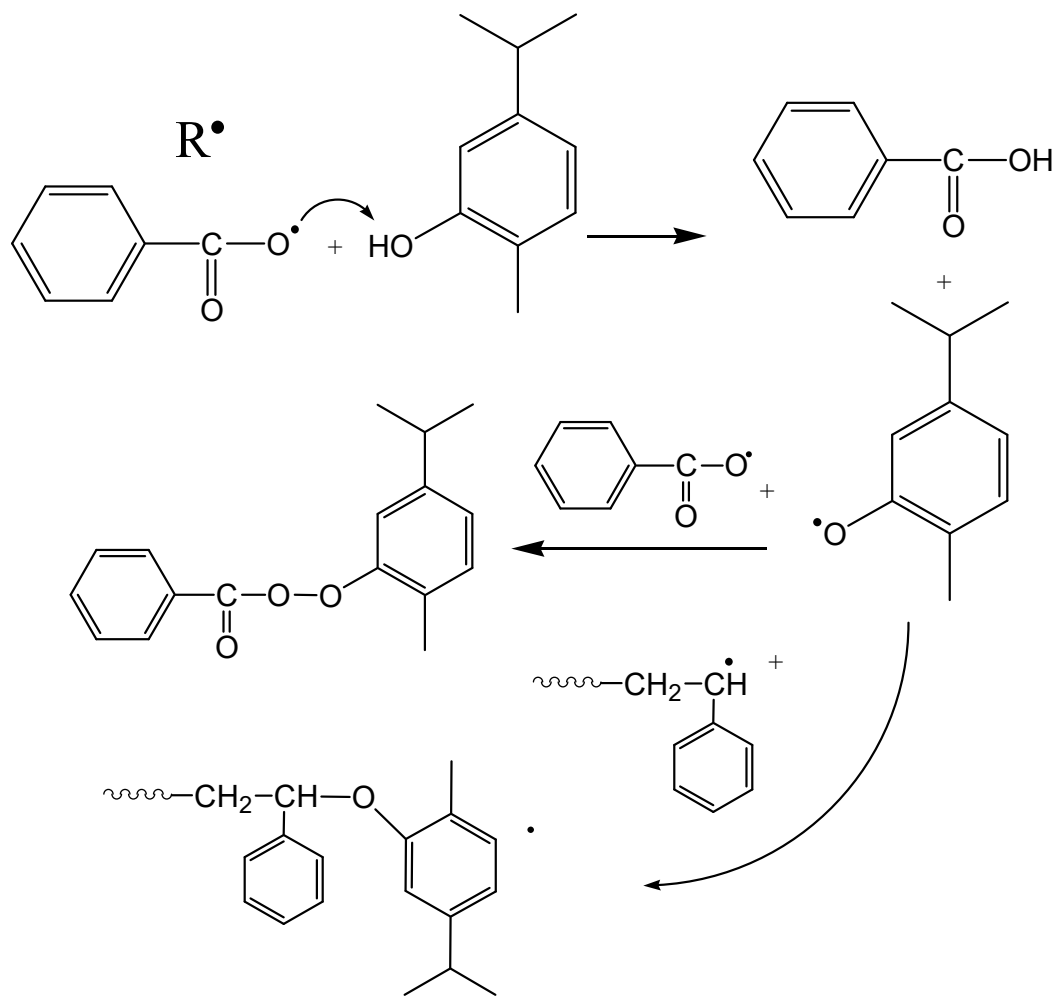

Scheme 3. Possible reaction mechanism of the phenoxy radicals formed from the reaction of an initiator primary radicals, $\mathrm{R}^{*}$ with the hydroxyl groups of thymol or carvacrol present in $\mathrm{TO}$ or $\mathrm{OO}$ either with another primary initiator radical or with a macro-radical to form inactive species.

Table 3. Number- and weight-average molecular weights $\left(\bar{M}_{n}, \bar{M}_{w}\right)$, as well as polydispersity of the MWD (PD) of the composite materials based on PS and thymol, carvacrol and estragol at different relative-to-monomer amounts of $0.1,0.5$ and $1.0 \mathrm{wt} \%$.

\begin{tabular}{cccc}
\hline Sample & $\overline{\boldsymbol{M}}_{\boldsymbol{n}}$ & $\overline{\boldsymbol{M}}_{\boldsymbol{w}}$ & PD \\
\hline PS & 37,120 & 77,590 & 2.09 \\
PS/Thym0.1 & 38,240 & 81,070 & 2.12 \\
PS/Thym0.5 & 44,880 & 101,430 & 2.26 \\
PS/Thym1.0 & 54,770 & 154,990 & 2.83 \\
PS/Carv0.1 & 38,270 & 83,420 & 2.18 \\
PS/Carv0.5 & 46,830 & 101,610 & 2.17 \\
PS/Carv1.0 & 51,930 & 144,360 & 2.78 \\
PS/Estr0.1 & 37,170 & 80,290 & 2.16 \\
PS/Estr0.5 & 36,800 & 79,500 & 2.16 \\
PS/Estr1.0 & 38,390 & 81,400 & 2.12 \\
\hline
\end{tabular}



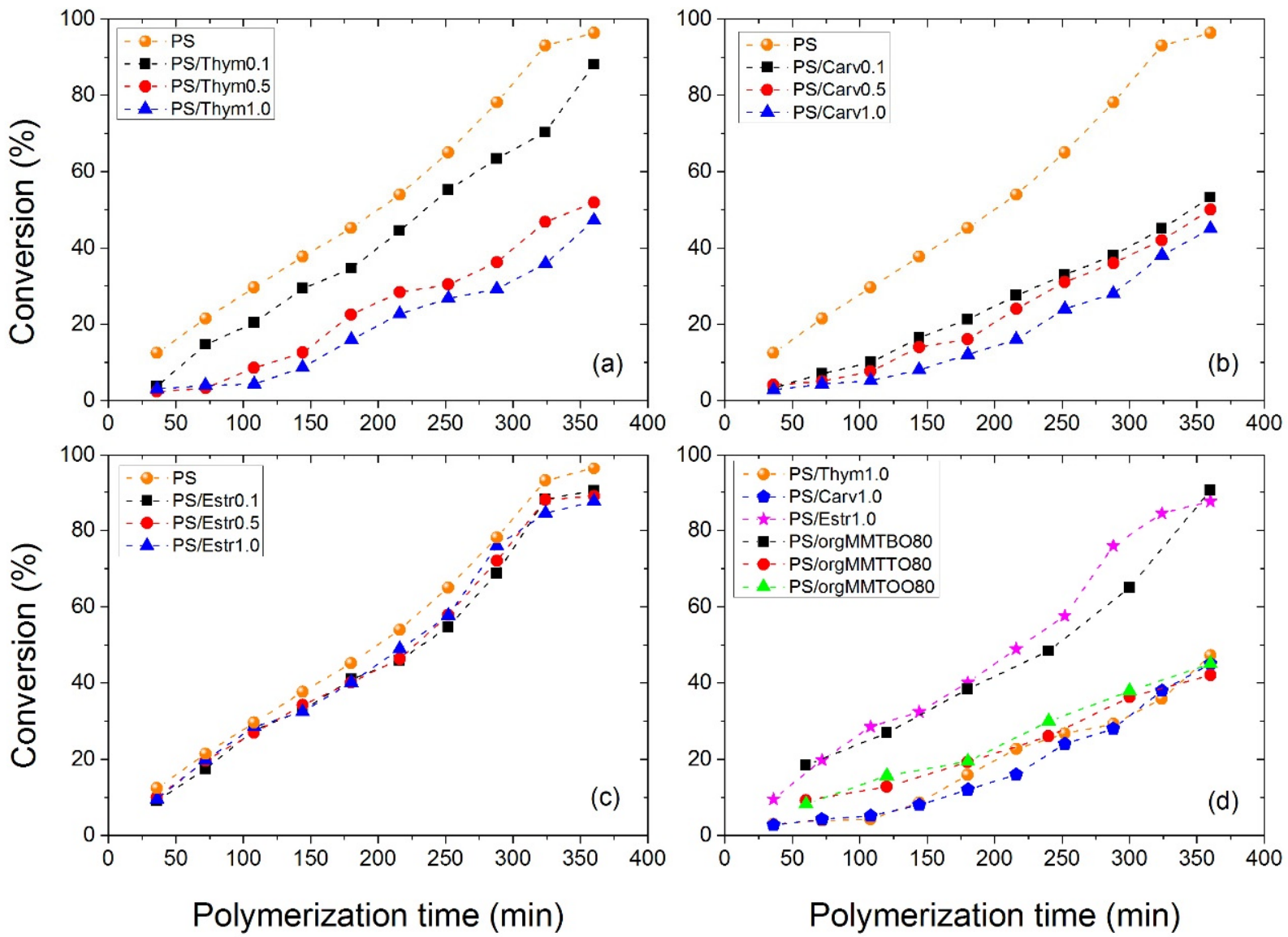

Figure 7. Variation of monomer conversion with time during polymerization of styrene with $0.1,0.5$ and $1.0 \mathrm{wt} \%$ of model thymol (a), carvacrol (b) and estragol (c) at $80{ }^{\circ} \mathrm{C}$ with $0.03 \mathrm{~mol} / \mathrm{L}$ initial BPO concentration. The downright figure (d) presents comparative results of model compounds at 1.0\% with orgMMTBO80, orgMMTTO80 and orgMMTOO80.

\subsection{Thermal Properties of the Materials Produced}

A "nano-effect" eminent in the literature related to the thermal properties of a polymer, has been the change in the glass transition temperature, $\mathrm{Tg}$ of the polymer matrix with the addition of nanosized particles. Depending upon the interaction between the matrix and the particle, both increase and decrease in the Tg have been reported [35]. In addition, the technique used for the preparation of the nanocomposite (i.e., solution casting, melt mixing or in situ polymerization) has been shown to affect $\mathrm{Tg}$, with the in situ polymerization resulting usually to higher values [35,42]. Typical thermograms, obtained after the second heating, of neat PS and PS/orgMMT, PS/orgMMTTO60 and PS/orgMMTTO80 are presented in Figure 8 . The values of $\mathrm{Tg}$, marked in this figure and included in Table 2 are determined by the half $\mathrm{Cp}$ extrapolation method. In this research, the glass transition temperature of neat polystyrene was measured $94.5^{\circ} \mathrm{C}$, which is a typical value for this polymer $[40,42]$. The Tg value was increased to $97^{\circ} \mathrm{C}$ when orgMMT was added and further increased to values between 98 and $100{ }^{\circ} \mathrm{C}$ when the organomodified clay with the essential clays was added. Moreover, the Tg with the NaMMT was slightly increased to $96{ }^{\circ} \mathrm{C}$ and when the NaMMT with the EO added Tg increased again to values varying between 97 and $100{ }^{\circ} \mathrm{C}$. An increase of the $\mathrm{Tg}$ of PS from 94.2 to $96.5{ }^{\circ} \mathrm{C}$ when $3 \%$ of silica nanoparticles added was also reported in literature [42]. Furthermore, addition of $1 \%$ graphene oxide increased the $\mathrm{Tg}$ of PS from 90 to $96.8^{\circ} \mathrm{C}$ [40]. The increase of $\mathrm{Tg}$ of polystyrene due to the presence of the clay is ascribed to the confinement of intercalated PS chains within the silicate galleries that prevents the segmental motions of the polymer chains. 


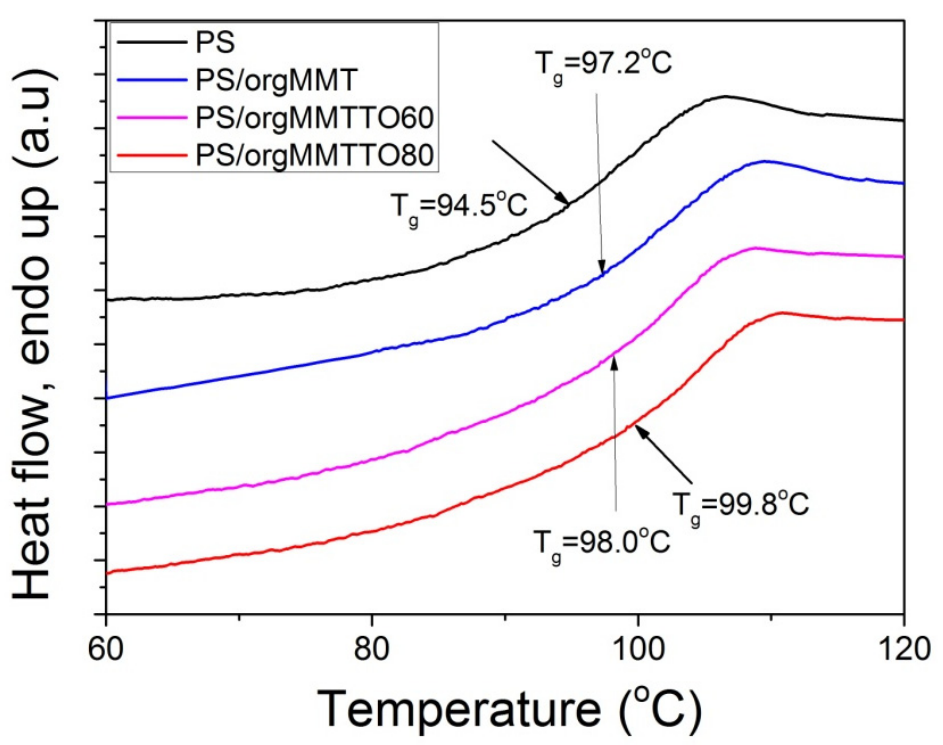

Figure 8. Indicative differential scanning calorimetry (DSC) data showing the estimation of the glass transition temperature, $\mathrm{Tg}$ of PS and some of its nanocomposites.

Finally, thermogravimetric analysis in inert atmosphere was used to investigate the effect of the MMTEO on the thermal stability of neat PS. The variation of mass loss with temperature of both PS/orgMMTEO and PS/NaMMTEO recorded via TGA, appears in Figure 9. In the same figure differential TGA curves are also included. Specific temperatures where $4 \%$ and $20 \%$ degradation occurs, $\mathrm{T}_{4 \%}, \mathrm{~T}_{20 \%}$ together with the temperature where degradation occurs at a maximum rate, $\mathrm{T}_{\max }$, appear in Table 4 . In general, degradation starts around $385^{\circ} \mathrm{C}$ and ends at $460-470{ }^{\circ} \mathrm{C}$ leaving a residual mass at $600{ }^{\circ} \mathrm{C}$, near zero for neat PS and around 2.0\% for the MMT nanocomposites (Table 4). The reliability of the experiments was verified from literature data. As an example, the $T_{\max }$ measured here for neat PS was $435^{\circ} \mathrm{C}$ which is very close to the value $437^{\circ} \mathrm{C}$ measured at the same heating rate recently by Blanco et al. [46].

Table 4. TGA data of neat PS and its nanocomposites with the sodium and orgno-modified MMT with or without the essential oils. Temperatures at $4 \%$ and $20 \%$ degradation, as well as at the maximum degradation rate, $\mathrm{T}_{4 \%}, \mathrm{~T}_{20}$ and $\mathrm{T}_{\max }$ and residual mass at $600{ }^{\circ} \mathrm{C}$.

\begin{tabular}{ccccc}
\hline Sample & $\mathbf{T}_{\mathbf{4} \%}\left({ }^{\circ} \mathbf{C}\right)$ & $\mathbf{T}_{\mathbf{2 0} \%}\left({ }^{\circ} \mathbf{C}\right)$ & $\mathbf{T}_{\max }\left({ }^{\circ} \mathbf{C}\right)$ & Residual at $\mathbf{6 0 0}{ }^{\circ} \mathbf{C}$ \\
\hline PS & 390 & 415 & 435 & 0.0 \\
PS/orgMMT & 397 & 419 & 437 & 1.8 \\
PS/orgMMTBO60 & 400 & 428 & 448 & 2.3 \\
PS/orgMMTTO60 & 383 & 430 & 450 & 2.0 \\
PS/orgMMTOO60 & 387 & 432 & 452 & 2.2 \\
PS/orgMMTBO80 & 379 & 417 & 442 & 2.1 \\
PS/orgMMTTO80 & 380 & 416 & 437 & 2.0 \\
PS/orgMMTOO80 & 370 & 420 & 438 & 1.8 \\
PS/NaMMT & 390 & 415 & 441 & 2.3 \\
PS/NaMMTBO60 & 393 & 419 & 437 & 1.8 \\
PS/NaMMTTO60 & 375 & 417 & 437 & 2.0 \\
PS/NaMMTOO60 & 388 & 420 & 438 & 1.5 \\
PS/NaMMTBO80 & 390 & 418 & 437 & 1.6 \\
PS/NaMMTTO80 & 365 & 412 & 439 & 1.7 \\
PS/NaMMTOO80 & 388 & 421 & 437 & \\
\hline
\end{tabular}



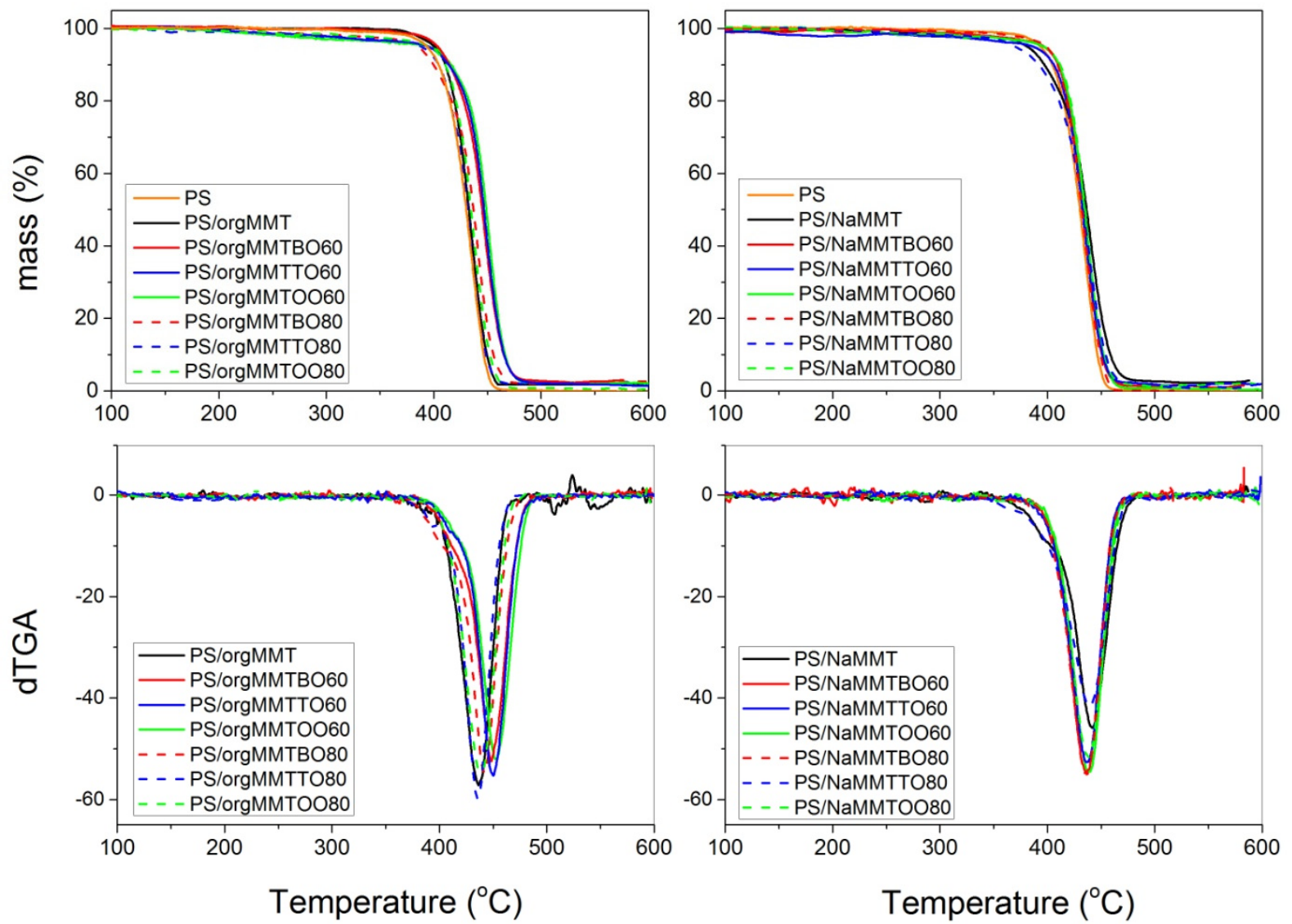

Figure 9. Mass loss and differential thermogravimetric analysis (TGA) curves obtained during heating at $20^{\circ} \mathrm{C} / \mathrm{min}$ of neat PS and PS/orgMMTEO and PS/NaMMTEO nanocomposites with various types of added essential oils.

The thermal degradation of radically prepared polystyrene in an inert atmosphere has long been studied in literature, with most researchers reporting that the dominating mechanism is that of random scission of the carbon-carbon main chain [40,47]. In Figure 9, the differential TGA curves showed a single peak in most of the materials studied denoting thus a single-step degradation mechanism. The nano-hybrids of PS with the organomodified montmorillonite presented a slight enhancement in the thermal stability compared to neat PS. This can be seen from the $\mathrm{T}_{20} \%$ values, where the value measured for PS, i.e., $415^{\circ} \mathrm{C}$, increased to $419^{\circ} \mathrm{C}$ in the PS/orgMMT and further to $430{ }^{\circ} \mathrm{C}$ in the nanocomposites with $60 \mathrm{EO}$, whereas when the amount of the EO increased to 80 this values decreased to $416-420{ }^{\circ} \mathrm{C}$. A similar trend was observed in the $\mathrm{T}_{\max }$ values. Enhanced thermal properties for nanocomposites of polystyrene with organomodified clays have also been observed by other researchers $[41,48]$. The origin of this increase in the degradation temperatures when MMT is added in the polymer matrix has been attributed to the ability of nanometer silicate layers to obstruct volatile gas produced by thermal decomposition. Accordingly, thermal decomposition begins from the surface of the nanocomposites, leading in an increase of the orgMMT content and the formation of a 'protection layer' by the clay. This, so-called 'barrier model' works well for char-forming polymers but it seems to not hold for non-char-forming polymers such as PMMA or PS $[49,50]$. In this case, the phenomenon can be better described using the nanoconfinements theory [49,50]. Accordingly, with the start of polymer degradation the newly formed radicals are nanoconfined, permitting a variety of bimolecular reactions to occur. As degradation progresses, a decrease in the surface free energy results in a migration of the clay platelets gradually to the surface forming the barrier that has been detected experimentally. The emission of volatile degradation products is prevented by the distributed orgMMT sheets acting as block layers. Meanwhile, the degraded small gas molecules which cannot diffuse in time would restrain the reaction of 
PS, leading to a higher temperature at the same mass loss. In addition, PS thermal stability can be improved from the absorption of a part of the polymer chains with low degree of degradation at the interface between polymer and MMT [51]. In the NaMMT samples the thermal degradation curves were similar to that of neat PS. A possible presence of small amounts of tactoids in the partially exfoliated structure of sodium nanocomposite could account for the not so-much increase in the decomposition rate observed in these materials.

In order to check if orgMMT itself or the materials with the orgMMTEO are responsible to the above findings further TGA experiments were carried out using again only the model compounds, thymol, carvacrol and estragol, which are the main constituents of the EOs studied. The results appear in Figure 10. It is clear that all the materials produced exhibit lower thermal stability compared to neat PS as can be observed form degradation staring at lower temperatures. Particularly, as the amount of thymol, carvacrol or estragol increases thermal degradation starts at much lower temperatures. Therefore, it can be concluded that using only the model compounds present in the EOs will definitely result in materials with much lower thermal degradation. It is the presence of MMT and specifically of the organomodified MMT which retains the polymer original properties or sometimes results in enhanced thermal stability.
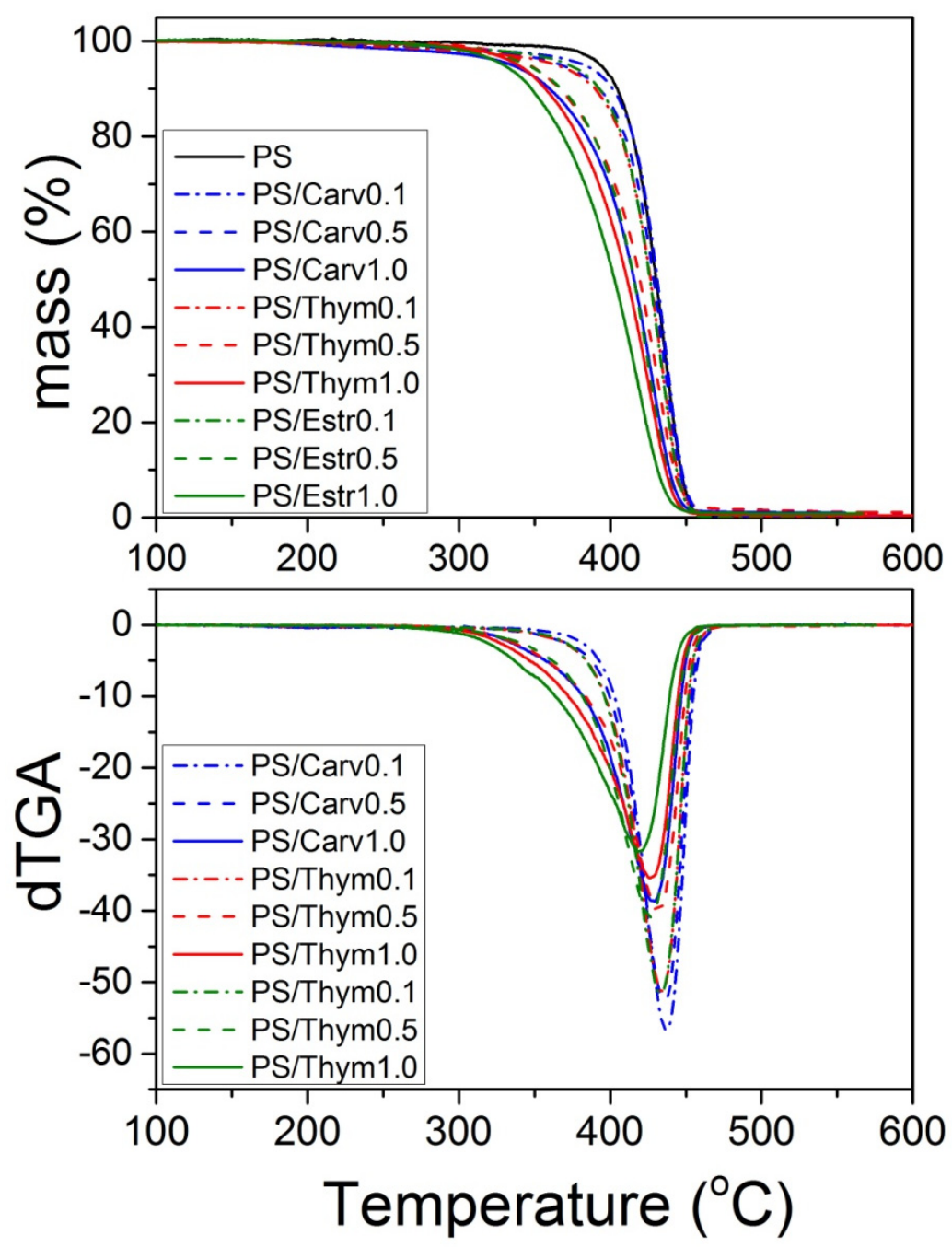

Figure 10. Mass loss and differential TGA curves obtained during heating at $20^{\circ} \mathrm{C} / \mathrm{min}$ of PS with model thymol, carvacrol and estragol at $0.1,0.5$ and $1.0 \mathrm{wt} \%$. 


\section{Conclusions}

This research is in the general framework of producing active plastic packaging using bio-based additives with antioxidant properties. The in situ bulk polymerization was investigated as a promising technique, not requiring high temperatures or toxic solvents, in order to incorporate additives containing possibly volatile materials into a polymer matrix. The radical polymerization of styrene was investigated in the presence of sodium montmorillonite (NaMMT) and organo-modified montmorillonite (orgMMT) including thyme (TO), oregano (OO), and basil (BO) essential oil at nominal composition $60 \%$ and $80 \%$. Polymerization kinetics was investigated by measuring the variation of monomer conversion with time gravimetrically, as well as the molecular weight distribution and average molecular weights of the polymer formed via GPC. Better dispersion was observed when orgMMT was added instead of NaMMT. Using X-ray diffraction it was found that mainly intercalated structures are obtained when using the organically modified montmorillonite whereas mainly exfoliated when the NaMMT was employed. the incorporation of the MMTEO in the polymer matrix was verified via FTIR spectroscopy. It was found that the hydroxyl groups present in thymol and carvacrol which are the main ingredients of thyme oil and oregano oil participate in side retardation reactions leading to lower polymerization rate accompanied by higher polymer average molecular weight. This was attributed to the reactions of the primary initiator radicals with the hydroxyl groups resulting in decreased initiator efficiency. Use of basil oil, which mainly includes estragol and not active hydroxyl groups, did not seem to affect significantly the polymerization kinetics and polymer MWD. The glass transition temperature (measured from DSC) and the thermal stability (from TGA) of the nanocomposites formed were slightly increased from 95 to $98{ }^{\circ} \mathrm{C}$ and from 435 to $445^{\circ} \mathrm{C}$, respectively.

Furthermore, in order to discriminate between the effect of the MMT itself or the characteristic compounds of the essential oils on the reaction kinetics and polymer properties, additional experiments carried out using styrene and model thymol, carvacrol and estragol this time. Similar polymerization kinetics was observed when using model compounds of the chemicals included in large amounts in the essential oils with those obtained from the hybrids of orgMMTEO. In contrast, the enhancement of the thermal stability was mainly the result of the nanoclays, since using only the model compounds the thermal stability of the materials significantly decreased.

Therefore it seems that mainly the organically modified montmorillonite based materials can be used in this technique and be successfully incorporated into a polymer matrix in order to provide inherent antioxidant activity in a polymer matrix to be used in active food packaging.

Author Contributions: Conceptualization, A.E.G. and D.S.A.; data curation, I.S.T.; formal analysis, D.S.A.; investigation, I.S.T., A.L., S.C. and C.E.S.; methodology, I.S.T., A.E.G. and D.S.A.; project administration, A.E.G. and D.S.A.; resources, A.E.G. and D.S.A.; software, D.S.A.; supervision, D.S.A.; validation, I.S.T., A.L., S.C., C.E.S. and A.E.G.; visualization, I.S.T. and D.S.A.; writing-original draft, D.S.A.; writing - review and editing, A.E.G. and D.S.A. All authors have read and agreed to the published version of the manuscript.

Funding: This research received no external funding.

Acknowledgments: The authors are thankful to Athanasios Ladavos for fruitful discussions and George Constantinou for carrying some of the experiments.

Conflicts of Interest: The authors declare no conflict of interest.

\section{References}

1. Sánchez-González, L.; Vargas, M.; González-Martínez, C.; Chiralt, A.; Cháfer, M. Use of Essential Oils in Bioactive Edible Coatings: A Review. Food Eng. Rev. 2011, 3, 1-16. [CrossRef]

2. Vilarinho, F.; Vaz, M.F.; Silva, A.S. The use of montmorillonite (MMT) in food nanocomposites: Methods of incorporation, characterization of MMT/polymer nanocomposites and main consequences in the properties. Recent Pat. Food Nutr. Agric. 2020, 11, 13-26. [CrossRef] [PubMed] 
3. Souza, V.G.L.; Pires, J.R.A.; Rodrigues, C.; Rodrigues, P.F.; Lopes, A.; Silva, R.J.; Caldeira, J.; Duarte, M.P.; Fernandes, F.B.; Coelhoso, I.M.; et al. Physical and morphological characterization of chitosan/montmorillonite films incorporated with ginger essential oil. Coatings 2019, 9, 700. [CrossRef]

4. Souza, V.G.L.; Pires, J.R.A.; Vieira, É.T.; Coelhoso, I.M.; Duarte, M.P.; Fernando, A.L. Activity of chitosan-montmorillonite bionanocomposites incorporated with rosemary essential oil: From in vitro assays to application in fresh poultry meat. Food Hydrocoll. 2019, 89, 241-252. [CrossRef]

5. Micó-Vicent, B.; Viqueira, V.; Ramos, M.; Luzi, F.; Dominici, F.; Torre, L.; Jiménez, A.; Puglia, D.; Garrigós, M.C. Effect of lemon waste natural dye and essential oil loaded into laminar nanoclays on thermomechanical and color properties of polyester based bionanocomposites. Polymers 2020, 12, 1451. [CrossRef]

6. Tornuk, F.; Sagdic, O.; Hancer, M.; Yetim, H. Development of LLDPE based active nanocomposite films with nanoclays impregnated with volatile compounds. Food Res. Int. 2018, 107, 337-345. [CrossRef]

7. Giannakas, A.; Tsagkalias, I.; Achilias, D.S.; Ladavos, A. A novel method for the preparation of inorganic and organo-modified montmorillonite essential oil hybrids. Appl. Clay Sci. 2017, 146, 362-370. [CrossRef]

8. Giannakas, A. Na-Montmorillonite vs. Organically Modified Montmorillonite as Essential Oil Nanocarriers for Melt-Extruded Low-Density Poly-Ethylene Nanocomposite Active Packaging Films with a Controllable and Long-Life Antioxidant Activity. Nanomaterials 2020, 10, 1027. [CrossRef]

9. Giannakas, A.; Ladavos, A. Preparation and Characterization of Polystyrene/Organolaponite Nanocomposites. Polym. Plast. Technol. Eng. 2012, 51, 1411-1415. [CrossRef]

10. Elshafie, H.S.; Camele, I. An Overview of the Biological Effects of Some Mediterranean Essential Oils on Human Health. Biomed Res. Int. 2017, 2017, 1-14. [CrossRef]

11. Wińska, K.; Mączka, W.; Łyczko, J.; Grabarczyk, M.; Czubaszek, A.; Szumny, A. Essential Oils as Antimicrobial Agents-Myth or Real Alternative? Molecules 2019, 24, 2130. [CrossRef] [PubMed]

12. Méndez-Vilas, A. Microbial Pathogens and Strategies for Combating Them: Science, Technology and Education; Formatex Research Center: Norristown, PA, USA, 2013; ISBN 9788493984397.

13. Vokou, D.; Kokkini, S.; Bessiere, J.-M. Geographic variation of Greek oregano (Origanum vulgare ssp. hirtum) essential oils. Biochem. Syst. Ecol. 1993, 21, 287-295. [CrossRef]

14. Stefanaki, A.; Cook, C.M.; Lanaras, T.; Kokkini, S. The Oregano plants of Chios Island (Greece): Essential oils of Origanum onites L. growing wild in different habitats. Ind. Crop. Prod. 2016, 82, 107-113. [CrossRef]

15. Wei, H.-K.; Chen, G.; Wang, R.-J.; Peng, J. Oregano essential oil decreased susceptibility to oxidative stress-induced dysfunction of intestinal epithelial barrier in rats. J. Funct. Foods 2015, 18, 1191-1199. [CrossRef]

16. Lambert, R.J.W.; Skandamis, P.N.; Coote, P.J.; Nychas, G.J.E. A study of the minimum inhibitory concentration and mode of action of oregano essential oil, thymol and carvacrol. J. Appl. Microbiol. 2001, 91, 453-462. [CrossRef]

17. Teixeira, B.; Marques, A.; Ramos, C.; Serrano, C.; Matos, O.; Neng, N.R.; Nogueira, J.M.; Saraiva, J.A.; Nunes, M.L. Chemical composition and bioactivity of different oregano (Origanum vulgare) extracts and essential oil. J. Sci. Food Agric. 2013, 93, 2707-2714. [CrossRef]

18. Perdones, A.; Chiralt, A.; Vargas, M. Properties of film-forming dispersions and films based on chitosan containing basil or thyme essential oil. Food Hydrocoll. 2016, 57, 271-279. [CrossRef]

19. Borugă, O.; Jianu, C.; Mişcă, C.; Goleț, I.; Gruia, A.T.; Horhat, F.G. Thymus vulgaris essential oil: Chemical composition and antimicrobial activity. J. Med. Life 2014, 7, 56-60.

20. Bozin, B.; Mimica-Dukic, N.; Simin, N.; Anackov, G. Characterization of the volatile composition of essential oils of some lamiaceae spices and the antimicrobial and antioxidant activities of the entire oils. J. Agric. Food Chem. 2006, 54, 1822-1828. [CrossRef]

21. Politeo, O.; Jukic, M.; Milos, M. Chemical composition and antioxidant capacity of free volatile aglycones from basil (Ocimum basilicum L.) compared with its essential oil. Food Chem. 2007, 101, 379-385. [CrossRef]

22. Opalchenova, G.; Obreshkova, D. Comparative studies on the activity of basil-An essential oil from Ocimum basilicum L.-against multidrug resistant clinical isolates of the genera Staphylococcus, Enterococcus and Pseudomonas by using different test methods. J. Microbiol. Methods 2003, 54, 105-110. [CrossRef]

23. Hussain, A.I.; Anwar, F.; Sherazi, S.T.H.; Przybylski, R. Chemical composition, antioxidant and antimicrobial activities of basil (Ocimum basilicum) essential oils depends on seasonal variations. Food Chem. 2008, 108, 986-995. [CrossRef] [PubMed]

24. Su, H.J.; Chao, C.J.; Chang, H.Y.; Wu, P.C. The effects of evaporating essential oils on indoor air quality. Atmos. Environ. 2007, 41, 1230-1236. [CrossRef]

25. Campos-Requena, V.H.; Rivas, B.L.; Pérez, M.A.; Garrido-Miranda, K.A.; Pereira, E.D. Polymer/clay nanocomposite films as active packaging material: Modeling of antimicrobial release. Eur. Polym. J. 2015, 71, 461-475. [CrossRef]

26. Giannakas, A.E.; Leontiou, A.A. Montmorillonite Composite Materials and Food Packaging. In Composites Materials for Food Packaging; John Wiley \& Sons: Hoboken, NJ, USA, 2018; pp. 1-71. ISBN 978-1-119-16024-3.

27. Kinninmonth, M.A.; Liauw, C.M.; Verran, J.; Taylor, R.; Edwards-Jones, V.; Shaw, D.; Webb, M. Investigation into the suitability of layered silicates as adsorption media for essential oils using FTIR and GC-MS. Appl. Clay Sci. 2013, 83-84, 415-425. [CrossRef]

28. El Miz, M.; Salhi, S.; El Bachiri, A.; Wathelet, J.; Tahani, A. Adsorption of essential oil components of Lavandula angustifolia on sodium modified bentonite from Nador (North-East Morocco). Afr. J. Biotechnol. 2015, 13, 3413-3425. 
29. El Miz, M.; Salhi, S.; Chraibi, I.; El Bachiri, A.; Fauconnier, M.-L.; Tahani, A. Characterization and adsorption study of thymol on pillared bentonite. Open J. Phys. Chem. 2014, 4, 98-116. [CrossRef]

30. Nguemtchouin, M.G.; Ngassoum, M.B.; Chalier, P.; Kamga, R.; Ngamo, L.S.; Cretin, M. Ocimum gratissimum essential oil and modified montmorillonite clay, a means of controlling insect pests in stored products. J. Stored Prod. Res. 2013, 52, 57-62. [CrossRef]

31. Alexandre, M.; Dubois, P. Polymer-layered silicate nanocomposites: Preparation, properties and used of a new class of materials. Mater. Sci. Eng. R Rep. 2000, 28, 1-63. [CrossRef]

32. Tiwari, R.R.; Natarajan, U. Thermal and mechanical properties of melt processed intercalated poly(methyl methacrylate)organoclay nanocomposites over a wide range of filler loading. Polym. Int. 2008, 57, 738-743. [CrossRef]

33. Kumar, S.; Jog, J.P.; Natarajan, U. Preparation and characterization of poly(methyl methacrylate)-clay nanocomposites via melt intercalation: The effect of organoclay on the structure and thermal properties. J. Appl. Polym. Sci. 2003, 89, 1186-1194. [CrossRef]

34. Dhibar, A.K.; Mallick, S.; Rath, T.; Khatua, B.B. Effect of clay platelet dispersion as affected by the manufacturing techniques on thermal and mechanical properties of PMMA-clay nanocomposites. J. Appl. Polym. Sci. 2009, 113, 3012-3018. [CrossRef]

35. Nikolaidis, A.K.; Achilias, D.S.; Karayannidis, G.P. Synthesis and characterization of PMMA/organomodified montmorillonite nanocomposites prepared by in situ bulk polymerization. Ind. Eng. Chem. Res. 2011, 50, 571-579. [CrossRef]

36. Achilias, D.S.; Siafaka, P.; Nikolaidis, A.K. Polymerization Kinetics and Thermal Properties of Poly(alkyl methacrylate)/Organomodified Montmorillonite Nanocomposites. Polym. Int. 2012, 61, 1510-1518. [CrossRef]

37. Verros, G.D.; Achilias, D.S. Towards the development of a mathematical model for the bulk in situ radical polymerization of methyl methacrylate in the presence of nano-additives. Can. J. Chem. Eng. 2016, 94, 1783-1791. [CrossRef]

38. Siddiqui, M.N.; Redhwi, H.H.; Vakalopoulou, E.; Tsagkalias, I.; Ioannidou, M.D.; Achilias, D.S. Synthesis, characterization and reaction kinetics of PMMA/silver nanocomposites prepared via in situ radical polymerization. Eur. Polym. J. 2015, 72, 256-269. [CrossRef]

39. Tsagkalias, I.S.; Vlachou, A.; Verros, G.D.; Achilias, D.S. Effect of Graphene oxide or Functionalized Graphene Oxide on the Copolymerization Kinetics of Styrene/n-butyl Methacrylate. Polymers 2019, 11, 999. [CrossRef] [PubMed]

40. Tsagkalias, I.; Proskynitopoulou, V.; Verros, G.D.; Achilias, D.S. Effect of graphene oxide on the kinetics of the radical polymerization of styrene. Materials today Proc. 2018, 5, 27517-27525. [CrossRef]

41. Majoni, S. Thermal and flammability study of polystyrene composites containing magnesium-aluminum layered double hydroxide (MgAl-C16 LDH), and an organophosphate. J. Therm Anal. Calorim 2015, 120, 1435-1443. [CrossRef]

42. Bera, O.; Pilic, B.; Pavlicevic, J.; Jovicic, M.; Holló, B.; Mészáros Szécsényi, K.; Spirkova, M. Preparation and thermal properties of polystyrene/silica nanocomposites. Thermochim. Acta 2011, 515, 1-5. [CrossRef]

43. Achilias, D.S. A review of modeling of diffusion controlled polymerization reactions. Macromol. Theory Simul. 2007, 16, 319-347. [CrossRef]

44. Siddiqui, M.N.; Redhwi, H.H.; Verros, G.D.; Achilias, D.S. Evaluating the role of nanomontmorillonite in bulk in situ radical polymerization kinetics of butyl methacrylate through a simulation model. Ind. Eng. Chem. Res. 2014, 53, 11303-11311. [CrossRef]

45. Michailidis, M.; Verros, G.D.; Deliyanni, E.; Andriotis, E.G.; Achilias, D.S. An experimental and theoretical study of butyl methacrylate in situ radical polymerization kinetics in the presence of graphene oxide nanoadditive. J. Polym. Sci. Part A Polym. Chem. 2017, 55, 1433-1441. [CrossRef]

46. Blanco, I.; Cicala, G.; Tosto, C.; Bottino, F.A. Kinetic Study of the Thermal and Thermo-Oxidative Degradations of Polystyrene Reinforced with Multiple-Cages POSS. Polymers 2020, 12, 2742. [CrossRef] [PubMed]

47. Peterson, J.D.; Vyazovkin, S.; Wight, C.A. Kinetics of the Thermal and Thermo-Oxidative Degradation of Polystyrene, Polyethylene and Poly(propylene). Macromol. Chem. Phys. 2001, 202, 775-784. [CrossRef]

48. Suresh, K.; Kumar, R.V.; Kumar, M.; Jeyapriya, M.; Anbarasan, R.; Pugazhenthi, G. Sonication-assisted synthesis of polystyrene (PS)/organoclay nanocomposites: Influence of clay content. Appl. Nanosci. 2017, 7, 215-223. [CrossRef]

49. Chen, K.; Wilkie, C.A.; Vyazovkin, S. Nanoconfinement revealed in degradation and relaxation studies of two structurally different polystyrene-clay systems. J. Phys. Chem. B 2007, 111, 12685-12692. [CrossRef]

50. Vyazovkin, S.; Dranca, I.; Fan, X.; Advincula, R. Degradation and relaxation kinetics of polystyrene-clay nanocomposites prepared by surface-initiated polymerization. J. Phys. Chem. B 2004, 108, 11672-11679. [CrossRef]

51. Wang, Y.; Liao, X.; Li, S.; Luo, Y.; Yang, Q.; Li, G. Poly(methyl methacrylate nanocomposites based on graphene oxide: A comparative investigation of the effects of surface chemistry on properties and foaming behavior. Polym. Int. 2016, 65, 1195-1203. [CrossRef] 